\title{
Histological Effect of Formaldehyde as Food Preservative on Cerebellar Cortex of Albino Rat
}

\author{
HAYAM M. FARHOUD, M.D.; AMANY M. ABO OUF, M.D. and HEBA A. ABO EL-SOUD, M.Sc. \\ The Department of Anatomy \& Embryology, Faculty of Medicine for Girls, Al-Azhar University
}

\begin{abstract}
Background: Formaldehyde is an important chemical compound that is used widely in the industrial and medical setting. It is illegally used in excess amounts to preserve various kinds of foods that can affect the central nervous system particularly the cerebellar cortex.
\end{abstract}

Aim of Study: This work aims to evaluate the extent of histological changes of the cerebellar cortex of albino rat's offspring that may be induced by oral administration of formaldehyde to their mothers throughout pregnancy and lactation or direct administration to the offspring itself.

Material and Methods: The maximum dietary dose of formaldehyde $(41.9 \mathrm{mg} /$ person/day) was used in this work. The used doses according to rat age were $0.74 \mathrm{mg} /$ adult, $0.104 \mathrm{mg} /{ }^{2}$ weeks and $0.240 \mathrm{mg} / 4$ weeks. In this work, 42 pregnant albino rats and 120 of their offspring were used. They divided into 2 main groups; control and treated groups. The control group (Group C) consisted of 12 pregnant rats and 60 of their offspring. They were divided equally into $\mathrm{C} 1$, $\mathrm{C} 2$ and $\mathrm{C} 3$. The treated group (Group T) consisted of 30 pregnant rats and 60 of their offspring. They were divided equally into $\mathrm{T} 1, \mathrm{~T} 2$ and $\mathrm{T} 3$. The pregnant rats of $\mathrm{C} 1$ and $\mathrm{T} 1$ received distilled water and formaldehyde respectively throughout pregnancy and for 2 weeks after delivery, then the 2 weeks old offspring received distilled water and formaldehyde respectively till the end of 8 weeks. The delivered rats of $\mathrm{C} 2$ and $\mathrm{T} 2$ received distilled water and formaldehyde respectively for 2 weeks. Then the 2 weeks old offspring received distilled water and formaldehyde respectively till the end of 8 weeks. The 2 weeks old offspring of $\mathrm{C} 3$ and $\mathrm{T} 3$ received distilled water and formaldehyde respectively till the end of 8 weeks. The cerebelli of all groups were extracted at two ages, at 4 and 8 weeks and immersed into suitable fixatives then prepared for light microscopic examination, in addition, the cerebelli of 8 weeks offspring were used for electron microscopic examination and morphometric studies.

Results: In the present work, oral administration of formaldehyde induced delayed development of all layers of the cerebellar cortex in form of irregularity and change in the shape and size of cells, decreased the thickness of its layers. It also induced degenerative changes in the form of cytoplasmic

Correspondence to: Dr. Hayam M. Farhoud, The Department of Anatomy \& Embryology, Faculty of Medicine for Girls, Al-Azhar University vacuoles, pyknosis, ill-defined nuclei, fragmented cytoplasmic processes, dilated rough endoplasmic reticulum, dilated Golgi apparatus, mitochondria with destructed cristae, and presence of areas of ill-defined structures.

Conclusion: It could be concluded that the oral administration of formaldehyde caused delayed development and induced different histological changes in the cerebellar cortex of albino rat's offspring. These effects were directly proportional with the duration of its administration.

Key Words: Formaldehyde - Pregnant - Albino rats - Cerebellum - Offspring.

\section{Introduction}

FORMALDEHYDE is a chemical substance with a pungent odor and is highly soluble in water. It is present naturally in all cells, tissues and body fluids. The external exposure to the formaldehyde occurs maximally in the work environment [1] Formaldehyde is widely used in the industrial and histopathology laboratories. The solid form of formaldehyde is called paraformaldehyde, whereas the liquid form is known as formalin. In industry, the formaldehyde is widely used in plastics, insulators, dyes, textiles, rubbers, cables and wood. In medicine the formaldehyde is used in embalming and fixation of cadavers and tissues, it is also used for preserving some drugs, dental coating material and sterilization in the hospitals. In addition, the formaldehyde is used in the formation of deodorants, toothpaste, ink, paper and cosmetic products [2] . Catalytic oxidation of formaldehyde to $\mathrm{CO}_{2}$ and $\mathrm{H}_{2} \mathrm{O}$ under ambient condition is highly desired for purifying indoor air quality [3]. Formaldehyde is metabolized into formic acid within 90 seconds after its ingestion in the liver and the erythrocytes. The half-life of the formic acid is reported to be 90 minutes. Formic acid can be accumulated to reach a high concentration as rapidly as $30 \mathrm{~min}$ after ingestion. The high concentrations of the formic acid can rapidly necrosis the cells of the 
liver, the kidneys, the heart and the brain. The formic acid can be excreted in the urine as sodium salt or through the respiratory system after its oxidation to carbon dioxide and water $[\mathbf{1 , 4}]$. In recent days, the use of formaldehyde has alarmingly been increased in Egypt specifically in milk, cheese (as food preservative) and bean to accelerate the time of cooking and many other food items without control. This misuse exposes the majority of the population to severe health risk.

This work aims to evaluate the extent of histological changes of the cerebellar cortex of albino rat's offspring that may be induced by oral administration of formaldehyde to their mothers throughout pregnancy and lactation or direct administration to the offspring itself.

\section{Material and Methods}

\section{Material:}

Fifty six adult Wister albino rats (42 female and 14 male) in addition to their offspring (120) were used in this work. The average weight of the adult rats was about $180-200 \mathrm{gm}$, the weight of 2 weeks offspring albino rat was about 26-28gm and the weight of 4 weeks offspring albino rat was about $60-65 \mathrm{gm}$. They were obtained and provided by veterinary care by the Animal House of Faculty of Medicine for Girls, Al-Azhar University during 2017. Each male was kept with three females in a separate cage to allow matting. The female that showed a vaginal plug was considered to be in the first day of pregnancy [5]. Each pregnant rat was kept in a separate cage until delivery. The offspring were kept with their mothers for feeding until weaning. The Wister albino rat were observed and maintained on balanced diet and water (standard diet pellets El-Naser-Company, Abo-Zaabal-Egypt). The pellets were consisted of 5\% fibers, $3.5 \%$ fats, $6.5 \%$ ash and $20 \%$ proteins.

The pregnant rats were divided into two main groups; control and treated one.

\section{A- Control group (Group C):}

The control group consisted of 12 pregnant albino rats. Each pregnant rat delivered about 46 offspring, so 60 offspring were used. The pregnant rats and their offspring were divided equally into $\mathrm{C} 1, \mathrm{C} 2$ and $\mathrm{C} 3$. The pregnant rats and/or their offspring received a single oral daily dose of distilled water via a gastric tube as follow:

I- Cl: Each pregnant rat received $0.04 \mathrm{cc}$ of distilled water throughout pregnancy and for 2 weeks after delivery, and then the 2 weeks old offspring received $0.03 \mathrm{cc}$ of distilled water for another 2 weeks. The cerebelli of half of them were taken at the end of the 4 th week. The other half continued to receive $0.05 \mathrm{cc}$ of distilled water for another 4 weeks then their cerebelli were taken at the end of the 8 th week.

II- C2: Immediately after delivery, each delivered rat received $0.04 \mathrm{cc}$ of distilled water for 2 weeks. Then the 2 weeks old offspring received $0.03 \mathrm{cc}$ of distilled water for another 2 weeks. The cerebelli of half of them were taken at the end of the 4 th week. The other half continued to receive $0.05 \mathrm{cc}$ of distilled water for another 4 weeks then their cerebelli were taken at the end of the 8 th week.

III- C3: Two weeks after delivery, the 2 weeks old offspring received $0.03 \mathrm{cc}$ of distilled water for 2 weeks. The cerebelli of half of them were taken at the end of the 4 th week. The other half continued to receive $0.05 \mathrm{cc}$ of distilled water for another 4 weeks then their cerebelli were taken at the end of the 8 th week.

\section{B- Treated group (Group T):}

The treated group consisted of 30 pregnant albino rats. Each pregnant rat delivered about 24 offspring, so 60 offspring were used. The pregnant rats and their offspring were divided equally into $\mathrm{T} 1, \mathrm{~T} 2$ and $\mathrm{T} 3$. The pregnant rats and/or their offspring received a single oral daily dose of formaldehyde via a gastric tube as follow:

I- T1: Each pregnant rat received $0.74 \mathrm{mg}$ of formaldehyde dissolved in $0.04 \mathrm{cc}$ of distilled water throughout pregnancy and for 2 weeks after delivery and then the 2 weeks old offspring received 0.104 $\mathrm{mg}$ of formaldehyde dissolved in $0.03 \mathrm{cc}$ of distilled water/rat for 2 weeks. The cerebelli of half of them were taken at the end of the 4 th week. The other half continued to receive $0.240 \mathrm{mg}$ of formaldehyde dissolved in $0.05 \mathrm{cc}$ of distilled water/rat for another 4 weeks then their cerebelli were taken at the end of the 8 th week.

II- T2: Immediately after delivery, each delivered rat received $0.74 \mathrm{mg}$ of formaldehyde dissolved in $0.04 \mathrm{cc}$ of distilled water for 2 weeks. Then the 2 weeks old offspring received $0.104 \mathrm{mg}$ of formaldehyde dissolved in $0.03 \mathrm{cc}$ of distilled water/rat for 2 weeks. The cerebelli of half of them were taken at the end of the 4 th week. The other half continued to receive $0.240 \mathrm{mg}$ of formaldehyde dissolved in $0.05 \mathrm{cc}$ of distilled water/rat for another 4 weeks and their cerebelli were taken at the end of the 8 th week.

III- T3: Two weeks after delivery, the 2 weeks old offspring received $0.104 \mathrm{mg}$ of formaldehyde 
dissolved in $0.03 \mathrm{cc}$ of distilled water/rat for 2 weeks. The cerebelli of half of them were taken at the end of the 4 th week. The other half continued to receive $0.240 \mathrm{mg}$ of formaldehyde dissolved in $0.05 \mathrm{cc}$ of distilled water/rat for another 4 weeks and their cerebelli were taken at the end of the 8 th week.

\section{B- Methods:}

\section{Calculation of the formaldehyde dose:}

Formaldehyde was used as food preservative. The average dietary exposure of formaldehyde was about 4.35 to $41.9 \mathrm{mg}$ per person per day [6]. So, the maximum dietary exposure which is $41.9 \mathrm{mg} /$ person/day was used in this work. The formaldehyde concentration in the formalin solution was $37 \pm 1 \%$. Each $1 \mathrm{cc}$ of formalin solution contained $1090 \mathrm{mg}$ of formaldehyde [7-10]. So, the equivalent dose for adult albino rat was calculated according to the formula of Paget and Barnes [11]. The dose of formaldehyde for adult rat equals $0.74 \mathrm{mg} / \mathrm{rat}$, for 2 week old offspring $0.104 \mathrm{mg} / \mathrm{rat}$ and for 4 week old offspring $0.240 \mathrm{mg} / \mathrm{rat}$.

\section{Preparation of formaldehyde dose:}

$1 \mathrm{cc}$ of formalin solution contained 1090mg of formaldehyde. It diluted in $58 \mathrm{cc}$ of distilled water so, the diluted $1 \mathrm{cc}$ contained $18.474 \mathrm{mg}$. The adult rat received $0.04 \mathrm{cc}$ of distilled water which contained $0.74 \mathrm{mg}$ of formaldehyde. Repeated dilution of $1 \mathrm{cc}$ of the adult dose was done by adding $4 \mathrm{cc}$ of distilled water. So, each 1cc contained $3.6948 \mathrm{mg}$, the 2 week old offspring rat received $0.03 \mathrm{cc}$ of distilled water which contained $0.104 \mathrm{mg}$ of formaldehyde. Repeated dilution of $1 \mathrm{cc}$ of the adult dose was done by adding $3 \mathrm{cc}$ of distilled water so, each $1 \mathrm{cc}$ contained 4.6185 , and the 4 weeks old offspring rat received $0.05 \mathrm{cc}$ of distilled water which contained $0.240 \mathrm{mg}$ of formaldehyde.

\section{Collection of specimens and preparation for examination:}

The specimens were collected at two ages; at 4 weeks and 8 weeks. The all offspring were anaesthetized lightly by diethyl ether inhalation. Each rat of all groups was decapitated and the cap and side walls of the cranium were carefully removed. The dura mater was carefully incised all around then raised up then, the cerebelli were gently removed and rapidly immersed in suitable fixatives. Special care was done for the rats which their cerebelli were used for electron microscopic examination. The rats were injected intracranial with glutaraldehyde before decapitation of the skull cap and the specimens were taken so rapid while the rats still alive. The cerebelli of all groups were used for light microscopic examination, in addition the cerebelli of 8 weeks albino rats of all groups were used for electron microscopic examination and morphometric study.

\section{1- Light microscopic examination:}

The cerebelli which were used for light microscopic examination were fixed by immersion in Bouin's solution for 3 days [12]. The specimens were dehydrated in ascending grades of ethyl alcohol and cleared in benzene. The specimens were impregnated for three changes in paraffin and were finally embedded in paraffin wax. The paraffin blocks were cut into serial sagittal sections at 5 ick with a rotary microtome. Successive sagittal paraffin sections were attached to an albumenized glass slides. The haematoxylin and Eosin stain [13] was used to study the cerebellar architectures. The Holmes' method silver staining [14] was used to illustrate the nerve fibers. The images were taken by a microscope (Leica) DM750 connected to a digital camera in Anatomy Department, Faculty of Medicine for Girls, Al-Azhar University, Cairo, Egypt.

\section{2- Transmission electron microscopic examination:}

The superficial layers of the cerebelli which used for electron microscopic examination were cut into small pieces. The specimens were immediately fixed in cold 5\% glutaraldehyde and washed in $0.1 \mathrm{ml}$ phosphate buffer ( $\mathrm{PH} 7.2)$. Then, post fixed with $1 \%$ osmium tetraoxide (OsO4), dehydrated and embedded in epoxy resin. The semithin sections (1 mick) were cut on an LKB ultratome, stained with toluidine blue and examined by light microscope. Ultrathin sections $(60 \mathrm{~nm}$ thick) were cut, mounted on copper grids, and stained with uranyl acetate and lead citrate [13] The ultrathin sections were examined using a transmission electron microscope (JEOL1010 EX II, Japan) at the Regional Mycology and Biotechnology Centre, Al-Azhar University, Cairo, Egypt.

\section{3- Morphometric study:}

The image analyser computer system Leica Qwin 500 (England) at the Regional Mycology and Biotechnology Center, Al-Azhar University, Cairo, Egypt was used to evaluate the thickness of the molecular and the internal granular layers and the number of the Purkinje cells of the studied groups by using haematoxylin and eosin stained sections. The ten slides of ten offspring albino rats were taken at the mid-sagittal sections of all groups. The central five folia were selected in each slide to measure the thickness of the molecular and the internal granular layers and to count the number of Purkinje cells. Measuring the thickness was 
done by taking 6 different thicknesses for each folium at magnification X 200 using Image J software Version 1.48. Counting the number of Purkinje cells of the central five folia was done in special fixed squares. The means of the thickness of the molecular and the internal granular layers and the means of the numbers of the Purkinje cells of each folium were calculated. The cumulative mean thickness of the molecular and internal granular layers and mean number of the Purkinje cells for each group were calculated statistically. The data was subjected to statistical analysis.

\section{Statistical analysis:}

Statistical analysis of the thickness of the molecular and internal granular layers and the counted Purkinje cells were carried out using the SPSS statistical package, the data were analyzed and statistical significance was determined by using one-way ANOVA followed by a Tuckey post-Hoc test for multiple comparisons. $p$-value less than 0.05 were considered to be statistically significant [15].

\section{Results}

\section{Cerebellar cortex of 4 weeks old albino rat offspring:}

- Cerebellar cortex of 4 weeks old control offspring of C1, C2 and C3: Light microscopic examination of the cerebellar cortex of 4 weeks control albino rat offspring of C1, C2 and C3 showed no significant histological difference between them, so their data were pooled together.

Light microscopic examination of haematoxylin and eosin stained mid-sagittal sections of the cerebellar cortex of 4 weeks control albino rat showed that the cerebellar cortex consisted of 3 layers; the molecular layer, the Purkinje cell layer and the internal granular layer. The molecular layer lied beneath the pia mater, it consisted of 2 types of cells; stellate and basket cells. The stellate cells were present in the outer one third of the molecular layer. They appeared oval or rounded in shape of different size and had deeply stained basophilic nuclei with prominent nucleoli. The basket cells were present in the deep one third of the molecular layer and in between the Purkinje cells. They appeared oval or rounded in shape, variable in size and had lightly stained basophilic nuclei with prominent nucleoli. The middle third of the molecular layer contained both types of molecular cells. The Purkinje cells were arranged in a single row in between the molecular and internal granular layers. Most of them accepted their characteristic flask shape. They had large vesicular basophilic nuclei with prominent nucleoli. The internal granular layer consisted of granule cells which aggregated in clusters that were separated by small acidophilic areas. The cells were variable in size, rounded or oval in shape and had deeply stained basophilic nuclei with prominent nucleoli Fig. (1A). The sections of the cerebellar cortex which were stained with Holmes' method silver staining showed that the cytoplasmic processes of the molecular layer appeared distributed to different directions. The dendritic stems of the Purkinje cells were directed towards the molecular layer and gave rise to several branches. The axons were directed towards the internal granular layer. The cytoplasmic processes of the internal granular layer appeared long and distributed to different directions Fig. (2A).

- Cerebellar cortex of 4 weeks old offspring of T1: Light microscopic examination of haematoxylin and eosin stained mid-sagittal sections of the cerebellar cortex of 4 weeks old offspring of T1 which their mothers received formaldehyde throughout pregnancy and for 2 weeks after delivery, then the 2 weeks offspring received it till the end of 4 weeks showed that the cerebellar cortex consisted of 3 layers; the molecular layer, the Purkinje cell layer and the internal granular layer. The molecular layer lied just beneath the pia mater and its thickness apparently decreased than the control one Figs. $(1 \mathrm{~B}, \mathrm{~A})$. The stellate and basket cells were variable in size and shape. They appeared oval or rounded in shape with oval or rounded lightly stained nuclei. Most of them had vacuolated cytoplasm. While others appeared shrunken and had deeply stained nuclei. The Purkinje cells were arranged in a single row superficial to the internal granular layer and were widely separated from each other. The Purkinje cells appeared oval in shape with deeply stained nuclei and central nucleoli. Some of them had illdefined nuclei and others were surrounded by areas of vacuolations. The internal granular layer consisted of small rounded and oval granule cells of variable size. The granule cells were aggregated in clusters that were separated by small acidophilic areas. They had deeply stained nuclei with prominent nucleoli Fig. (1B). The sections of the cerebellar cortex which were stained with Holmes' method silver staining showed that the cytoplasmic processes of the molecular layer appeared few, short, fragmented and passed in different directions. The cytoplasmic processes of the Purkinje cells were poorly developed and could be recognized as thin and short processes. The cytoplasmic processes of the internal granular layer were few, short and poorly branched as compared with the control one Figs. (1B,2B). 
- Cerebellar cortex of 4 weeks old offspring of T2: Light microscopic examination of haematoxylin and eosin stained mid-sagittal sections of the cerebellar cortex of the 4 weeks old offspring of T2 which their mothers received the formaldehyde immediately after delivery for 2 weeks then the 2 weeks offspring received formaldehyde till the end of the 4 weeks showed that the cerebellar cortex consisted of 3 layers; the molecular layer, the Purkinje cell layer and the internal granular layer. The molecular layer lied beneath the pia mater and its thickness apparently decreased than the control one Figs. (1A,C). The stellate and basket cells appeared oval or rounded in shape, variable in size and have lightly stained nuclei. Some stellate cells were shrunken and had deeply stained nuclei. Also some of them had vacuolated cytoplasm. The vacuolations of the cytoplasm were more obvious in the basket cells which lied in between the Purkinj e cells. The Purkinje cells were few and widely separated from each other. Few cells exhibited the characteristic flask shape appearance while others appeared oval or irregular. All of them had deeply stained ill-defined nuclei. The internal granular layer consisted of small rounded and oval granule cells which were aggregated in clusters that were separated by small acidophilic areas. The granule cells had deeply stained nuclei with prominent nucleoli Fig. (1C). The sections of the cerebellar cortex which were stained with Holmes' method silver staining showed that the cytoplasmic processes of the molecular layer appeared short and fragmented. The identified cytoplasmic processes of the Purkinje cells appeared short and poorly developed. Some of them directed towards the molecular layer. The cytoplasmic processes of the internal granular layer appeared short and poorly developed as compared to the control one Figs. $(2 \mathrm{~A}, \mathrm{C})$.

- Cerebellar cortex of 4 weeks old offspring of T3: Light microscopic examination of haematoxylin and eosin stained mid-sagittal sections of the cerebellar cortex 4 weeks old offspring of T3 which received the formaldehyde from 2 weeks till the end of 4 weeks showed that the cerebellar cortex consisted of 3 layers; the molecular layer, the Purkinje cell layer and the internal granular layer Fig. (1D). The molecular layer lied beneath the pia mater and its thickness apparently decreased than the control one Figs. (1A,D). The stellate and basket cells appeared oval or rounded in shape, variable in size and most of them had lightly stained nuclei. Some molecular cells appeared small in size and had deeply stained shrunken nuclei while others had vacuolated cytoplasm. Most of the basket cells which lied in between the Purkinje cells had vacuolated cytoplasm. The majority of Purkinje cells were flask shape but they had illdefined or deeply stained nuclei. However, other cells appeared oval or irregular in shape and had ill-defined nuclei. Most of the Purkinje cells were surrounded by areas of vacuolations as compared with the control one. The internal granular layer consisted of small rounded and oval granule cells which were aggregated in clusters that were separated by small acidophilic areas. The granule cells had deeply stained nuclei and prominent nucleoli. Some cells were surrounded by areas of vacuolations Figs. (1A,D). The sections of the cerebellar cortex which were stained with Holmes' method silver staining showed that the cytoplasmic processes of the molecular layer appeared fragmented. The Purkinje cells had ill-defined cytoplasmic processes. The cytoplasmic processes of the internal granular layer could be recognized as short and ill-developed filaments as compared with the control one Figs. (2A,D).

Cerebellar cortex of 8 weeks old albino rat offspring:

- Cerebellar cortex of 8 weeks old control offspring of C1, C2 and C3: Examination of the cerebellar cortex of 8 weeks control albino rats of C 1, C2 and C3 showed no significant histological difference between them, so their data were pooled together.

Light microscopic examination of haematoxylin and eosin and toluidine blue stained mid-sagittal sections of the cerebellar cortex of 8 weeks control albino rat showed that the cerebellar cortex consisted of three layers; the molecular layer, the Purkinj e cell layer and the internal granular layer. The molecular layer lied beneath the pia mater and was markedly increased in thickness than the previous age Figs. (1A,3A). The molecular cells were variable in shape and size. The stellate cells which were present in the outer one third of the molecular layer appeared large with nearly ovoid or fusiform shape and had deeply stained basophilic nuclei with prominent nucleoli. The basket cells which were present in the deep one third of the molecular layer and in between the Purkinje cells appeared pyramidal or rounded in shape and had lightly stained basophilic nuclei with prominent nucleoli. The middle third of the molecular layer contained both types of cells. The Purkinje cells achieved their typical flask shaped appearance and had large vesicular basophilic central nuclei with prominent nucleoli. The dendrites were directed towards the molecular layer while the axons were directed towards the internal granular layer. The internal granular layer consisted of granule cells which 
were aggregated in clusters that were separated by small acidophilic areas. The granule cells appeared oval in shape and nearly equal in size. They had deeply stained basophilic nuclei with prominent nucleoli Figs. (3A,4A).

Electron microscopic examination of the cerebellar cortex of 8 weeks control albino rat showed that the molecular layer was composed of a complex network of neuronal cells and nerve fibers Figs. (5A,7A). The stellate cells had euchromatic nuclei with small clumps of heterochromatin with apparent nuclear pores and deep invaginations which contained free and clusters of ribosomes. Their cytoplasm contained free ribosomes, rough and smooth endoplasmic reticulum, mitochondria and Golgi apparatus Fig. (5A). The basket cells had large euchromatic nuclei with small clumps of heterochromatin with apparent nuclear pores. Their cytoplasm contained free ribosomes, rough endoplasmic reticulum and few mitochondria Fig. (6A). The neuropil of the molecular layer consisted of dendrites and axons. The dendrites contained free ribosomes, mitochondria, parallel microtubules and neurofilaments. The axons were varying in size and contained mitochondria and numerous rounded, or/and oval vesicles of varying size. There were symmetrical and asymmetrical types of synapses. The myelinated nerve fibers could also be seen Figs. (5A,7A). The Purkinje cells had euchromatic nuclei and eccentric nucleoli with apparent nuclear pores. Their cytoplasm was very rich in cytoplasmic organelles; free and clusters of ribosomes, numerous rough and smooth endoplasmic reticulum and mitochondria. The Bergmann astrocyte cells were observed close to the Purkinje cell bodies. They appeared rounded in shape and had euchromatic nuclei with small clumps of heterochromatin along their nuclear envelops. Their cytoplasm contained few organelles as free ribosomes, rough endoplasmic reticulum and mitochondria Fig. (8A). The granule cells were closed together, had large heterochromatic nuclei with eccentric nucleoli with apparent nuclear pores. Their cytoplasm contained, free ribosomes, few rough and smooth endoplasmic reticulum, mitochondria, Golgi apparatus and lysosomes. The neuropil of the internal granular layer was formed of dendrites, axons and synapses of symmetrical and asymmetrical types Fig. (9A).

- Cerebellar cortex of 8 weeks old offspring of T1: Light microscopic examination of haematoxylin and eosin and toluidine blue stained mid-sagittal sections of the cerebellar cortex of 8 weeks old offspring of T1 which their mothers received the formaldehyde throughout pregnancy and for 2 weeks after delivery, then the 2 weeks offspring received it till the end of 8 weeks showed that the cerebellar cortex consisted of 3 layers; the molecular layer, the Purkinje cell layer and the internal granular layer Fig. (3B). The molecular layer lied beneath the pia mater and its thickness was decreased than the control one Figs. (3A,B) and (Table 1) and Graph (1). The stellate and basket cells appeared oval or rounded in shape, variable in size and most of them had lightly stained nuclei. Some of them had deeply stained shrunken nuclei and others had vacuolated cytoplasm. Moreover, all the basket cells which lied in between the Purkinje cells had lightly stained nuclei and vacuolated cytoplasm Figs. (3B,4B). The Purkinje cells were few in number (Table 1) and Graph (1). They were widely separated from each other. Most of them exhibited their characteristic flask shape appearance and their long axes were directed perpendicular to the pia mater. However, the long axes of some cells were either parallel or oblique to the pia mater. Some Purkinje cells appeared shrunken and had deeply stained ill-defined nuclei. Also, most of them were surrounded by areas of vacuolations. The cytoplasmic processes appeared as small filaments which passed in different directions Figs. (3B,4B) as compared with the control Figs. (3A,4A). The internal granular layer consisted of rounded and oval granule cells which were aggregated in clusters that were separated by small acidophilic areas. The granule cells had deeply stained nuclei with prominent nucleoli. Some cells had vacuolated cytoplasm Figs. (3B,4B). The thickness of the internal granular layer was decreased than the control one (Table 1) and Graph (1).

Electron microscopic examination of the cerebellar cortex of 8 weeks old offspring of T1 showed that most of the stellate cells had irregular euchromatic nuclei with small clumps of heterochromatin with eccentric nucleoli, apparent nuclear pores and shallow and deep invaginations. Their cytoplasm contained free and clusters of ribosomes, rough endoplasmic reticulum and mitochondria Fig. (5B) as compared with the control Fig. (5A). The basket cells had euchromatic nuclei with small clumps of heterochromatin. Few cells had heterochromatic nuclei. The cytoplasm appeared swollen and poor in its cytoplasmic organelles. It contained free and small clusters of ribosomes, few dilated rough endoplasmic reticulum. Most of the mitochondria appeared swollen with destructed cristae. The signs of degeneration of the basket cells were manifested mainly on the cytoplasm, however, the nuclei were less affected as compared to the control one Figs. $(6 \mathrm{~A}, \mathrm{~B})$. The neuropil of the molecular layer consisted of dendrites and axons. Most of dendritic 
profiles were swollen and had dilated rough endoplasmic reticulum and mitochondria. Moreover, some dendritic profiles had areas of ill-defined structure. However, some dendrites appeared full of parallel fibers of microtubules and neurofilaments. The axons contained synaptic vesicles of varying size. There were synapses of symmetrical and asymmetrical types Figs. $(5 \mathrm{~B}, 6 \mathrm{~B}, 7 \mathrm{~B})$ as compared with the control Figs. (5A,7A). The Purkinje cells had heterochromatic nuclei with irregular nuclear envelope with ill-defined nuclear pores. The cytoplasmic organelles were condensed and compacted with each other and could hardly be differentiated. The differentiated organelles could be recognized as; few free and clusters of ribosomes, dilated rough endoplasmic reticulum and swollen Golgi apparatus. Also, some mitochondria appeared swollen with destructed cristae, others appeared dark with ill-defined cristae and few mitochondria had ill-defined outlines Fig. (8B). The signs of degeneration of the Purkinje cell were manifested on the cytoplasm and nucleus as compared with the control Fig. (8A). The majority of granule cells appeared irregular in shape and had heterochromatic nuclei with eccentric nucleoli. Their cytoplasm appeared swollen and contained few free ribosomes, few rough endoplasmic reticulum and few mitochondria Fig. (9B) as compared with the control Fig. (9A).

The neuropil of the Purkinje cell layer and the internal granular layer contained profiles of dendrites and axons. Most of the dendritic profiles were swollen and had areas of ill-defined organelles. There were synapses of symmetrical type. The cytoplasmic processes in between the granule cells appeared swollen and had ill-defined organelles. Myelinated nerve fibers could also be seen Figs. $(8 \mathrm{~B}, 9 \mathrm{~B})$.

- Cerebellar cortex of 8 weeks old offspring of T2: Light microscopic examination of haematoxylin and eosin and toluidine blue stained mid-sagittal sections of the cerebellar cortex of 8 weeks offspring of T2 which their mothers received the formaldehyde immediately after delivery for 2 weeks then the 2 weeks offspring received it till the end of the 8 weeks showed that the cerebellar cortex consisted of 3 layers; the molecular layer, the Purkinje cell layer and the internal granular layer. The molecular layer lied beneath the pia mater and its thickness was decreased than the control one Figs. (3A,C) and (Table 1) \& Graph (1). The stellate and basket cells appeared oval or rounded in shape and variable in size. Some stellate cells appeared shrunken and had small deeply stained nuclei with vacuolated cytoplasm. Moreo- ver, most of the basket cells which lied in between the Purkinje cells had vacuolated cytoplasm Figs. $(3 c, 4 c)$. The Purkinje cells were few in number Fig. (3C) and (Table 1) \& Graph (1). They were widely separated from each other and lost their characteristic flask shape and direction. They appeared elongated, oval or irregular in shape and their long axes appeared parallel to the pia mater. They had elongated nuclei and ill-defined nucleoli. The cytoplasm had homogenous eosinophilic appearance around the nuclei and surrounded by areas of vacuolations. The cytoplasmic processes could hardly be identified Figs. (3C,4C) as compared with the control Figs. (3A,4A). The granule cells appeared rounded or oval in shape and variable in size. They were aggregated in clusters that were separated by small acidophilic areas. They had deeply stained nuclei with prominent nucleoli. Few of them were surrounded by areas of vacuolations Figs. (3C,4C). The thickness of the internal granular layer was decreased than the control one (Table 1) \& Graph (1).

Electron microscopic examination of the cerebellar cortex of 8 weeks offspring of T2 showed that few stellate cells were nearly rounded in shape and have highly irregular heterochromatic nuclei with deep invaginations and ill-defined nuclear pores. The deep invaginations divided the nuclei incompletely into several parts filled with free ribosomes. Their cytoplasm contained free and clusters of ribosomes, few dilated rough endoplasmic reticulum and few mitochondria with destructed cristae. Also, there were areas of ill-defined structures Fig. (5C) as compared with the control Fig. (5A). The majority of the basket cells had euchromatic nuclei with small clumps of heterochromatin with apparent nuclear pores. Their cytoplasm was swollen and contained free and few clusters of ribosomes, few dilated rough endoplasmic reticulum, some mitochondria with destructed cristae and few swollen mitochondria with ill-defined outlines. The signs of affections of the basket cell were manifested mainly on the cytoplasm Fig. (6C) as compared with the control Fig. (6A). The neuropil of the molecular layer contained dendrites and axons. Some dendrites were swollen and had few ill-defined organelles. Others contained mitochondria, microtubules and neurofilaments. The axons could be identified with varying synaptic vesicles. There were synapses of symmetrical and asymmetrical types and myelinated nerve fibers Figs. (5C,6C,7C). The Purkinje cells had euchromatic nuclei with many shallow and deep invaginations with ill-defined nuclear pores and irregular and ill-defined nuclear envelops in some areas. Their cytoplasm contained free and clusters of 
ribosomes, few dilated rough endoplasmic reticulum, few mitochondria with destructed cristae, Golgi apparatus and areas with ill-defined structures Fig. (8C) as compared with the control Fig. (8A). The majority of granule cells had heterochromatic nuclei with eccentric nucleoli and apparent nuclear pores. Their cytoplasm contained free ribosomes, rough endoplasmic reticulum and few mitochondria. However, few granule cells appeared irregular in shape and had shrunken nuclei with highly condensed clumps of heterochromatin and wrinkled nuclear envelopes with ill-defined nuclear pores. Their cytoplasm appeared swollen and its cytoplasmic organelles could hardly be differentiated. However, few free ribosomes, few rough endoplasmic reticulum and mitochondria could hardly be detected. The neuropil of the internal granular layer contained dendrites, axons, symmetrical synapses and myelinated nerve fibers Fig. (9C).

- Cerebellar cortex of 8 weeks old offspring of T3: Light microscopic examination of haematoxylin and eosin and toluidine blue stained mid-sagittal sections of the cerebellar cortex 8 weeks offspring of T3 which received the formaldehyde from the 2 weeks till the end of 8 weeks showed that the cerebellar cortex consisted of 3 layers; the molecular layer, the Purkinj e cell layer and the internal granular layer. The molecular layer lied beneath the pia mater and its thickness decreased than the control one Figs. (3A,D) and (Table 1) \& Graph (1). The stellate and basket cells appeared oval or rounded in shape, variable in size and most of them had lightly stained nuclei. Some molecular cells appeared small in size and had deeply stained shrunken nuclei, while others had vacuolated cytoplasm. Most of the basket cells which lied in between the Purkinje cells had vacuolated cytoplasm Figs. (3D,4D) as compared with the control Figs. (3A,4A). The Purkinje cells were few in number (Table 1) and Graph (1). They were widely separated from each other. They lost their characteristic features; they appeared irregular in shape and small in size. The Purkinje cells had ill-defined nuclei and surrounded by areas of vacuolations. The broad bases of few cells were directed towards the pia mater while their tapering ends were directed towards the internal granular layer (upside down). So, their cytoplasmic processes passed in different directions Figs. (3D,4D). The thickness of the internal granular layer decreased than the control one (Table 1) and Graph (1). The granule cells appeared rounded or oval in shape and variable in size. They were aggregated in clusters that were separated by small acidophilic areas. They had deeply stained nuclei with prominent nucleoli Figs. (3D, 4D).
Electron microscopic examination of the cerebellar cortex of 8 weeks offspring of T3 showed that the cell membranes of some stellate cells were ill-defined in certain areas. They had oval euchromatic nuclei with many indentations and apparent nuclear pores. Their cytoplasm contained free and clusters of ribosomes, rough endoplasmic reticulum and few mitochondria with destructed cristae Fig. (5D). The basket cells had euchromatic nuclei with wrinkled nuclear envelopes and apparent nuclear pores. Their cytoplasm contained free and clusters of ribosomes, hardly detected rough endoplasmic reticulum and mitochondria with destructed cristae Fig. (6D) as compared with the control Fig. (6A). The neuropil of the molecular layer contained dendrites, axons and synapses of symmetrical and asymmetrical types. Some dendrites appeared swollen, they contained dilated rough endoplasmic reticulum and mitochondria, where some of them had destructed cristae. The dendritic spine could be detected. The axons contained synaptic vesicles of varying size Figs. (5D,7D). The Purkinje cells had euchromatic irregular nuclei with many deep invaginations and ill-defined nuclear pores. Their cytoplasm contained free ribosomes, few dilated rough endoplasmic reticulum and many mitochondria with destructed cristae Figs. (8D) as compared with the control Fig. (8A). Few granule cells appeared shrunken and had heterochromatic nuclei with condensed clumps of heterochromatin and apparent nuclear pores. Their cytoplasm contained free ribosomes, few small rough endoplasmic reticulum and few mitochondria with ill-defined cristae Fig. (9D) as compared with the control Fig. (9A). The neuropil the internal granular layer contained profiles of dendrites that had mitochondria with destructed cristae, axons and synapses of symmetrical and asymmetrical types Fig. (9D).

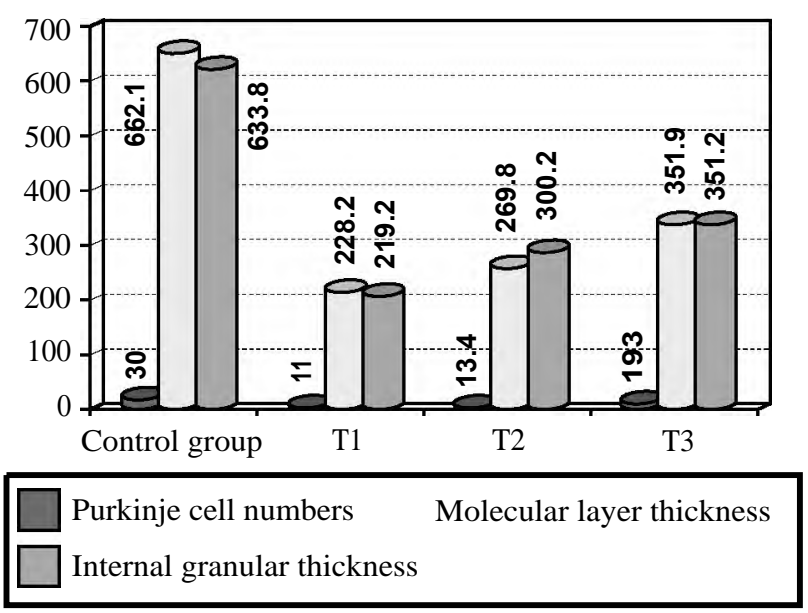

Graph (1): Bar chart representing the means of the number of the Purkinje cells, the thickness of the molecular layer and the thickness of the internal granular layer of the cerebellar cortex of the 8 weeks old offspring of the studied groups. 


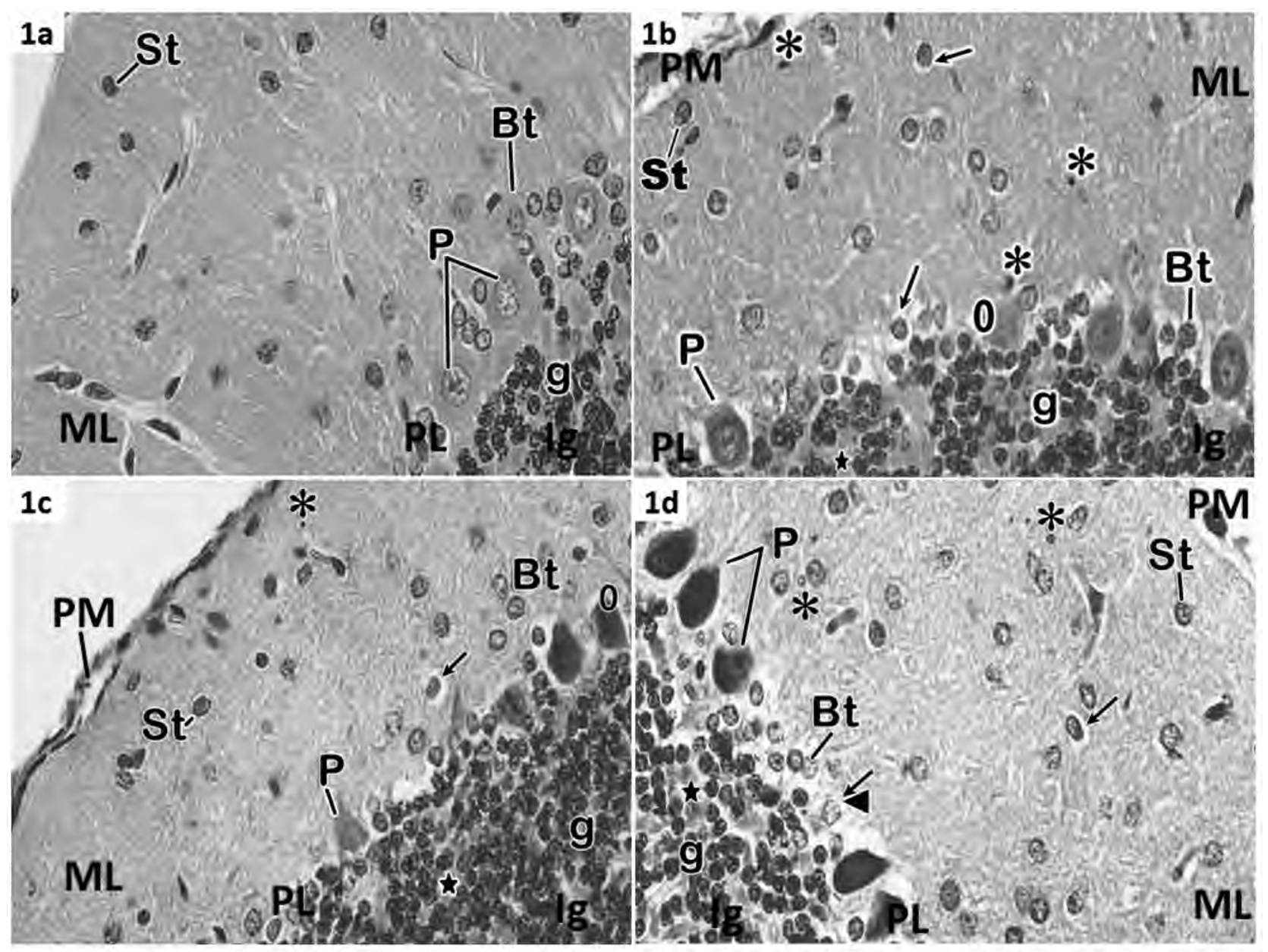

Fig. (1A): A photomicrograph of a median sagittal section of the cerebellar cortex of 4weeks control albino rat shows that the cerebellar cortex consists of molecular layer (ML), Purkinje cell layer (PC) and internal granular layer (Ig). The stellate cells $(\mathrm{St})$ have deeply stained basophilic nuclei. The basket cells $(\mathrm{Bt})$ have lightly stained basophilic nuclei. Notice that the Purkinje cells (P) appear flask in shape and have large vesicular basophilic nuclei with prominent nucleoli. The granule cells (g) have deeply stained basophilic nuclei with prominent nucleoli. (Hx. \& E.) X600.

Fig. (1B): A photomicrograph of a median sagittal section of the cerebellar cortex of 4 weeks albino rat of T3 shows that the cerebellar cortex consists of molecular layer (ML) lies beneath the pia mater (PM), Purkinje cell layer (PL) and internal granular layer (Ig). The stellate (St) and basket cells (Bt) appear oval or rounded in shape and most of them have vacuolated cytoplasm $(\downarrow)$. Some cells are shrunken and have deeply stained nuclei (*). The Purkinje cells $(P)$ appear oval in shape with deeply stained nuclei. Some cells have ill-defined nuclei $(0)$. Notice that the granule cells $(\mathrm{g})$ are arranged in clusters and separate by small acidophilic areas (star). (Hx. \& E.) X600.

Fig. (1C): A photomicrograph of a median sagittal section of the cerebellar cortex of 4 weeks albino rat of T2 shows that the cerebellar cortex consists of molecular layer (ML) lies beneath the pia mater (PM), Purkinje cell layer (PC) and internal granular layer $(\mathrm{Ig})$. The stellate $(\mathrm{St})$ and basket $(\mathrm{Bt})$ cells appear oval or rounded in shape, variable in size. Some stellate cells are shrunken and have deeply stained nuclei $\left({ }^{*}\right)$. Also, some molecular cells have vacuolated cytoplasm $(\downarrow)$. The Purkinje cells (P) appear few in number and are widely separated from each other. Few cells appear flask in shape and have deeply stained ill-defined nuclei $(0)$. The granule cells $(\mathrm{g})$ arrange in clusters that are separated by small acidophilic areas (star). (Hx. \& E.) X 600 .

Fig. (1D): A photomicrograph of a median sagittal section of the cerebellar cortex of 4 weeks albino rat of T3shows that the cerebellar cortex consists of molecular layer (ML) lies beneath the pia mater (PM), Purkinje cell layer (PC) and internal granular layer (Ig). The stellate $(\mathrm{St})$ and basket $(\mathrm{Bt})$ cells appear oval or rounded in shape and variable in size. Some of them appear shrunken and have deeply stained nuclei (*) while others have vacuolated cytoplasm $(\downarrow)$. Most of the basket cells which lie between the Purkinje cells have vacuolated cytoplasm $(\downarrow \nabla)$. Some of the Purkinje cells $(P)$ are flask shape, others appear irregular in shape. Both of them have ill-defined, deeply stained nuclei and are surrounded by areas of vacuolations. Notice also that the granule cells (g) arrange in clusters that are separated by small acidophilic areas (star). Some of them are surrounded by areas of vacuolations. (Hx. \& E) X 600 . 

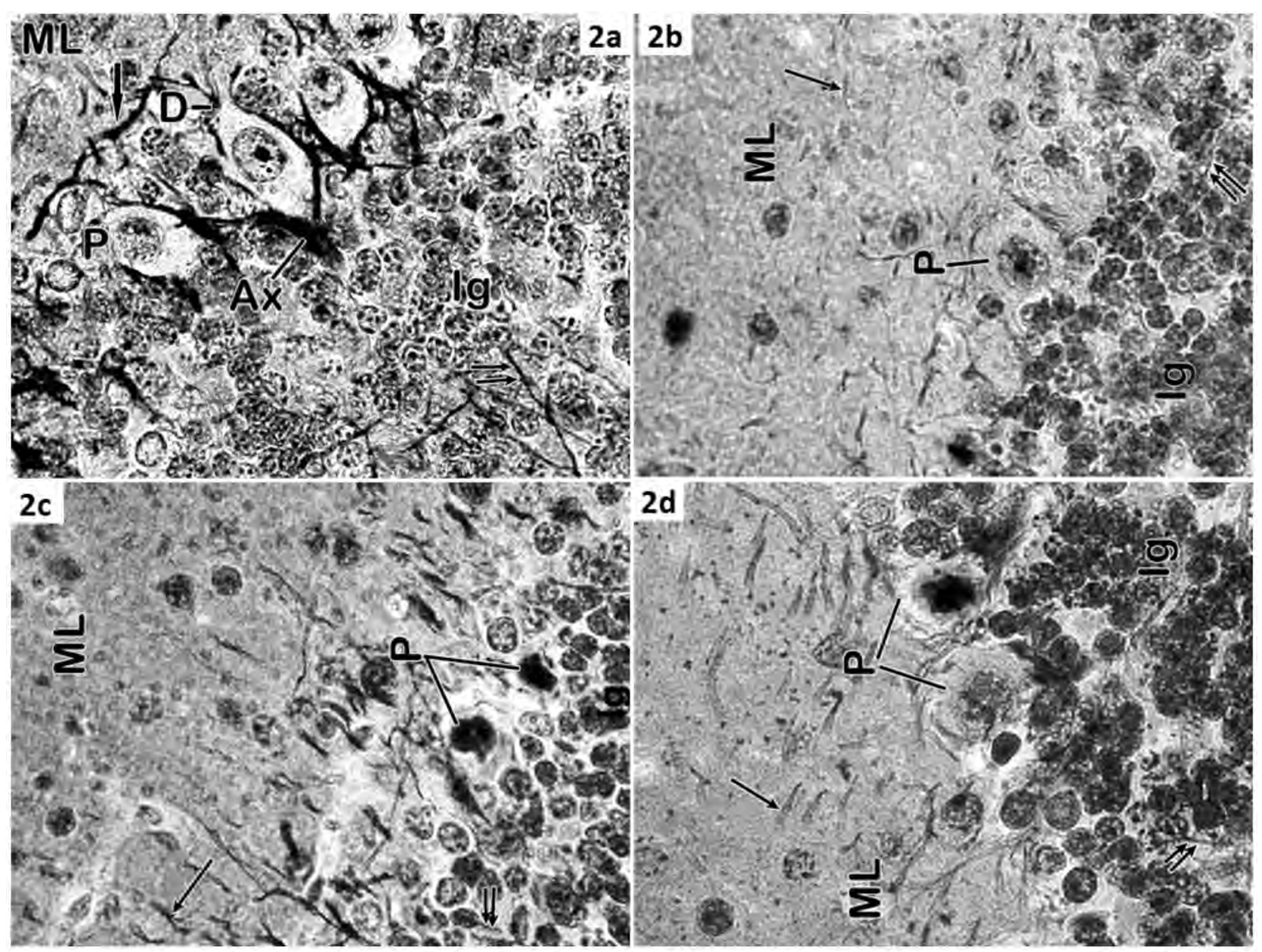

Fig. (2A): A photomicrograph of a median sagittal section of the cerebellar cortex of 4 weeks control albino rat shows that the cytoplasmic processes ( $\downarrow$ ) of the molecular layer (ML) appear as elongated brown filaments which distribute to different directions. The dendrites (D) of the Purkinje cells (P) are directed towards the molecular layer while the axons (Ax) are directed towards the internal granular layer. The cytoplasmic processes $(\downarrow \downarrow)$ of the internal granular layer (Ig) appear long and extend to different directions. (Holmes' method silver staining X 1000).

Fig. (2B): A photomicrograph of a median sagittal section of the cerebellar cortex of 4weeks albino rat of T1 shows that the cytoplasmic processes of the molecular layer (ML) are few, short and fragmented $(\downarrow)$. Notice that the cytoplasmic processes of the Purkinje cells (P) appear thin and short. The cytoplasmic processes of the internal granular layer (Ig) are few, short and poorly branched $(\downarrow \downarrow)$. (Holmes' method silver staining X 1000).

Fig. (2C): A photomicrograph of a median sagittal section of the cerebellar cortex of 4 weeks albino rat of T2 shows that the cytoplasmic processes of the molecular layer (ML) appear short and fragmented ( $\downarrow)$. Notice that the cytoplasmic processes of the Purkinje cells (P) and internal granular layer (Ig) appear short and poorly developed $(\downarrow \downarrow)$. (Holmes' method silver staining X 1000).

Fig. (2D): Photomicrograph of a median sagittal section of the cerebellar cortex of the 4weeks albino rat of T3 shows that the cytoplasmic processes ( $\downarrow)$ of the molecular layer (ML) appear fragmented. Also the cytoplasmic processes of the Purkinje cell (P) appear ill-developed. Notice also that the cytoplasmic processes $(\downarrow \downarrow)$ of the internal granular layer (Ig) appear short and poorly branched. (Holmes' method silver staining X 1000). 

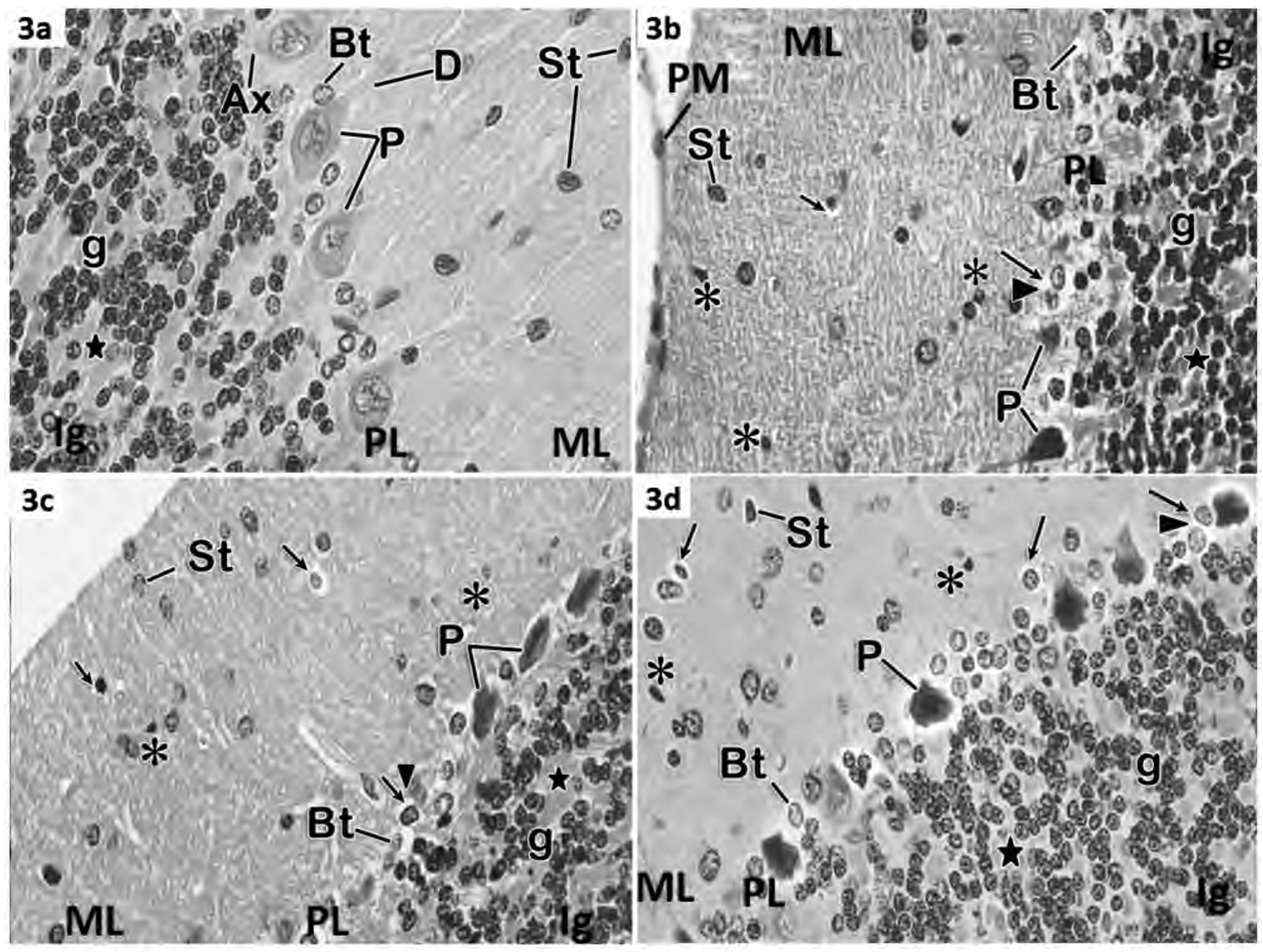

Fig. (3A): A photomicrograph of a median sagittal section of the cerebellar cortex of 8 weeks control albino rat shows that the cerebellar cortex consists of molecular layer (ML), Purkinje cell layer (PC) and internal granular layer (Ig). The stellate cells ( $\mathrm{St}$ ) have deeply stained basophilic nuclei. The basket cells $(\mathrm{Bt})$ have lightly stained basophilic nuclei. Notice that the Purkinje cells (P) appear flask in shape and have large vesicular basophilic central nuclei with prominent nucleoli. Their dendrites (D) are directed towards the molecular layer while their axons (Ax) are directed towards the internal granular layer. Notice also that the granule cells (g) aggregate in clusters that are separated by small acidophilic areas (star). They have deeply stained basophilic nuclei with prominent nucleoli. (H x. \& E.) X 600.

Fig. (3B): A photomicrograph of a median sagittal section of the cerebellar cortex of 8 weeks albino rat of T1 shows that the cerebellar cortex consists of molecular layer (ML) lies beneath the pia mater (PM), Purkinje cell layer (PC) and internal granular layer (Ig). The stellate $(\mathrm{St})$ and basket $(\mathrm{Bt})$ cells appear rounded or oval in shape and variable in size. Some cells are shrunken and have deeply stained nuclei $\left(^{*}\right)$ and others have vacuolated cytoplasm $(\downarrow)$. Moreover, all basket cells which lie in between the Purkinje cells have vacuolated cytoplasm $(\downarrow \nabla)$. Some Purkinje cells $(P)$ appear shrunken, have deeply stained illdefined nuclei and are surrounded by areas of vacuolations. Notice also that the granule cells (g) aggregate in clusters and separate by small acidophilic areas (star). Some of them have vacuolated cytoplasm. (H X. \& E.) X 600 .

Fig. (3C): A photomicrograph of a median sagittal section of the cerebellar cortex of 8 weeks albino rat of T2 shows that the cerebellar cortex consists of molecular layer (ML), Purkinje cell layer (PC) and internal granular layer (Ig). The stellate $(\mathrm{St})$ and basket $(\mathrm{Bt})$ cells appear oval or rounded in shape and variable in size. Some stellate cells appear shrunken and have deeply stained nuclei $(*)$. Other cells have vacuolated cytoplasm $(\downarrow)$. The basket cells which lie in between the Purkinje cells have obvious vacuolated cytoplasm ( $\downarrow \downarrow)$. The Purkinje cells (P) appear elongated, oval or irregular in shape and have elongated nuclei with ill-defined nucleoli. The cytoplasm has homogenous eosinophilic appearance around the nuclei and is surrounded by areas of vacuolations. Notice that the granule cells (g) aggregate in clusters and separate by small acidophilic areas (star). Few of them are surrounded by areas of vacuolations. (Hx. \& E.) X 600.

Fig. (3D): A photomicrograph of a median sagittal section of the cerebellar cortex of the 8 weeks albino rat of T3 shows that the cerebellar cortex consists of molecular layer (ML), Purkinje cell layer (PC) and internal granular layer (Ig). The stellate $(\mathrm{St})$ and basket $(\mathrm{Bt})$ cells appear oval or rounded in shape and variable in size. Some molecular cells appear small in size and have deeply stained shrunken nuclei $(*)$ while others have vacuolated cytoplasm $(\downarrow)$. Most of the basket cells which lie in between the Purkinje cells have vacuolated cytoplasm $(\nabla \downarrow)$. The Purkinje cells (P) appear irregular in shape, small in size and are surrounded by areas of vacuolations. The granule cells (g) aggregate in clusters and separate by small acidophilic areas (star). (Hx. \& E.) X 600 . 


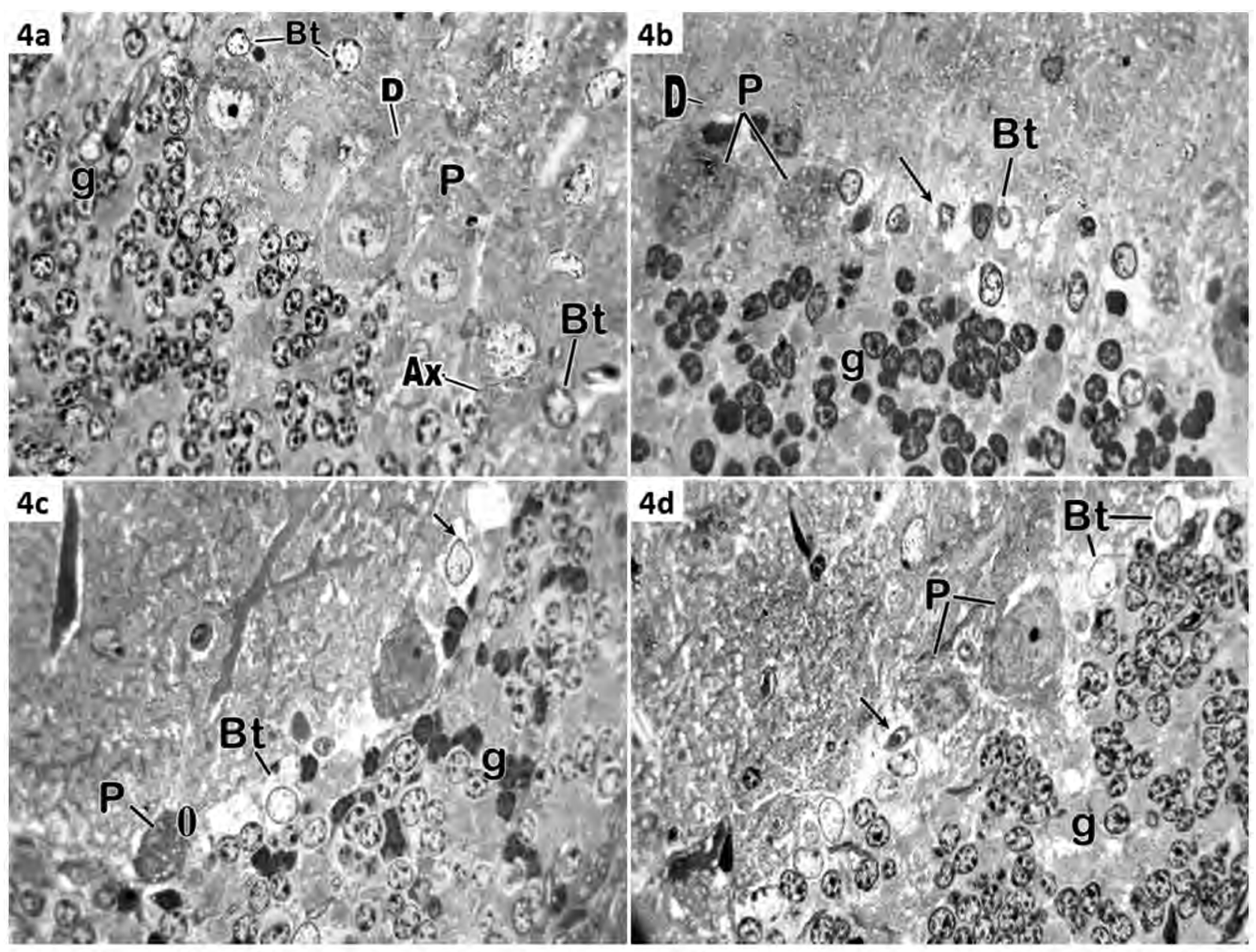

Fig. (4A): A photomicrograph of a semi-thin section of the cerebellar cortex of 8 weeks control albino rat shows that the basket cells $(\mathrm{Bt})$ have lightly stained nuclei with prominent nucleoli. The Purkinje cells $(\mathrm{P})$ have large vesicular central nuclei with prominent nucleoli. Their dendrites (D) are directed towards the molecular layer while their axons (Ax) are directed towards the internal granular layer. Notice also that the granule cells (g) aggregate in clusters and have deeply stained nuclei with prominent nucleoli. (Toluidine blue) X 1000.

Fig. (4B): A photomicrograph of a semi-thin section of the cerebellar cortex of 8 weeks albino rat of T1 shows that the basket cells $(\mathrm{Bt})$ appear variable in shape and size and have vacuolated cytoplasm $(\downarrow)$. The Purkinje cells (P) appear oval in shape and have ill-defined nuclei. The dendrite (D) of the Purkinje cell appears directed towards the molecular layer. Notice also that the granule cells (g) aggregate in clusters and variable in size. (Toluidine Blue X 1000).

Fig. (4C): A photomicrograph of a semi-thin section of the cerebellar cortex of 8 weeks albino rat of T4 shows that the basket cells (Bt) appear variable in shape and size and have vacuolated cytoplasm ( $\downarrow)$. The Purkinje cells (P) appear oval or irregular in shape and ill-defined nuclei $(0)$. Notice that the granule cells $(\mathrm{g})$ are aggregating in clusters. They are variable in size, shape and have deeply stained nuclei with prominent nucleoli. (Toluidine Blue X 1000).

Fig. (4D): A photomicrograph of semi-thin section of the cerebellar cortex of the 8 weeks albino rat of T5 shows that the basket cells (Bt) appear nearly oval in shape and have vacuolated cytoplasm $(\downarrow)$. The Purkinje cells $(P)$ are few in number, small and oval in shape and widely separated. Notice that the granule cells $(\mathrm{g})$ aggregate in clusters. They appear rounded or oval in shape and deeply stained nuclei with prominent nucleoli. (Toluidine Blue X 1000). 

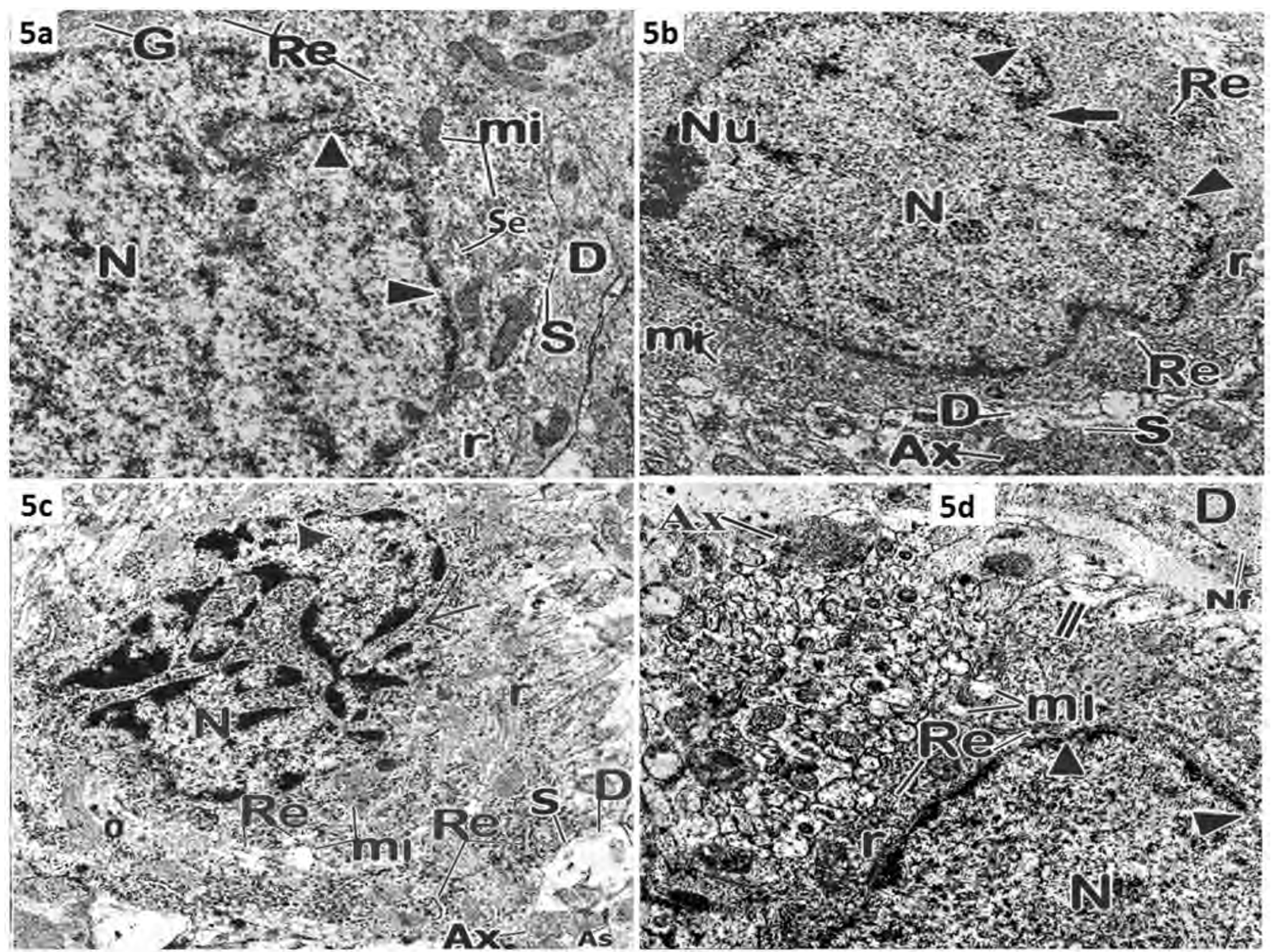

Fig. (5A): Electron micrograph of the molecular layer of 8 weeks control albino rat shows part of the stellate cell. Its nucleus (N) appears euchromatic with small clumps of heterochromatin and has apparent nuclear pores (A). Its cytoplasm contains free ribosomes (r), rough endoplasmic reticulum ( $\mathrm{Re}$ ), smooth endoplasmic reticulum (Se), mitochondria (mi) and Golgi apparatus (G). Notice also the presence of dendrite (D) and symmetrical (S) type of synapse. (X 15000).

Fig. (5B): Electron micrograph of the molecular layer of 8 weeks albino rat of T1 shows that the stellate cell has irregular, euchromatic nucleus with small clumps of heterochromatin $(\mathrm{N})$, eccentric nucleolus $(\mathrm{Nu})$ and many shallow and deep invaginations $(\downarrow)$. The nuclear envelope has apparent nuclear pores $(\boldsymbol{\Delta})$. Notice also that the cytoplasm contains free ribosomes $(\mathrm{r})$, dilated rough endoplasmic reticulum $(\mathrm{Re})$ and mitochondria (mi). Notice also the presence of dendrites (D), axon (Ax) and symmetrical (S) type of synapse. (X 15000).

Fig. (5C): Electron micrograph of the molecular layer of 8 weeks albino rat of $\mathrm{T} 2$ shows that the stellate cell has heterochromatic and highly irregular nucleus $(N)$ with many deep invaginations $(\downarrow)$ and hardly detected nuclear pores $(\boldsymbol{\Delta})$. Their cytoplasm contains free ribosomes ( $\mathrm{r}$ ), some dilated rough endoplasmic reticulum $(\mathrm{Re})$, few mitochondria (mi) with destructed cristae and ill-defined structure (0). Notice the presence of axons (Ax), dendrites (D) and symmetrical (S) and asymmetrical (As) synapses (X 15000).

Fig. (5D): Electron micrograph of the molecular layer of the 8 weeks albino rat of T5 shows that the stellate cell has euchromatic nucleus with apparent nuclear pores $(\boldsymbol{\Delta})$. Notice the presence of area of ill-defined cell membrane (=). Its cytoplasm contains free ribosomes (r), rough endoplasmic reticulum ( $R e)$ and mitochondria (mi) with destructed cristae. Notice the presence of axons (Ax) and dendrites (D) which contain microtubules and neurofilamentes (Nf). (X 15000). 

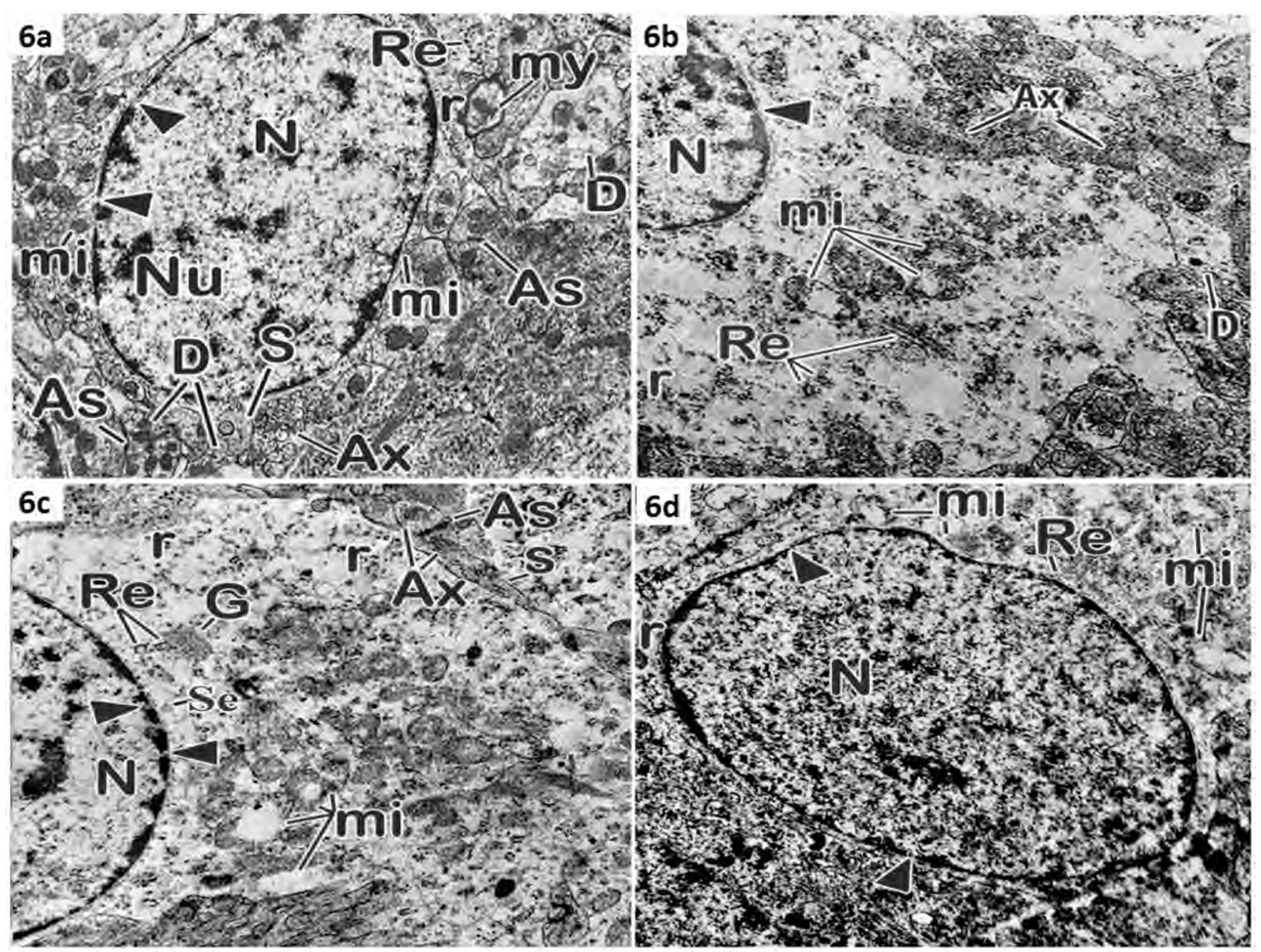

Fig. (6A): Electron micrograph of the molecular layer of 8 weeks control albino rat shows that the basket cell has oval euchromatic nucleus $(\mathrm{N})$ with small clumps of heterochromatin and eccentric nucleolus $(\mathrm{Nu})$ with apparent nuclear pores $(\mathbf{A})$. Its cytoplasm contains free ribosomes ( $r$ ), rough endoplasmic reticulum (Re) and mitochondria (mi). Notice the presence of dendrites (D), axons (Ax), myelinated nerve fibers (my) and synapses of symmetrical (S) and asymmetrical (As) types. (X 15000).

Fig, (6B): Electron micrograph of the molecular layer of 8 weeks albino rat of T3 shows that the nucleus (N) of the basket cell appears euchromatic with small clumps of heterochromatin and apparent nuclear pores $(\mathbf{\Delta})$. Notice that the cytoplasm appears swollen and contains free ribosomes (r), few dilated rough endoplasmic reticulum (Re), many the mitochondria (mi) with destructed cristae and few mitochondria with ill- defined outlines. Notice the presence of axons (Ax) and dilated dendrites (D). (X 15000).

Fig. (6C): Electron micrograph of the molecular layer of 8 weeks albino rat of T2 shows that the basket cell has euchromatic nucleus $(\mathrm{N})$ with small clumps of heterochromatin and apparent nuclear pores $(\mathbf{\Delta})$. Its cytoplasm is swollen and has widely distributed free ribosomes (r), Golgi apparatus $(\mathrm{G})$, few dilated rough endoplasmic reticulum (Re), smooth endoplasmic reticulum (Se) and mitochondria (mi) with destructed cristae. Notice the presence of axons (Ax), symmetrical (S) and asymmetrical (As) synapses. (X 15000).

Fig. (6D): Electron micrograph of the molecular layer of the 8 weeks albino rat of $\mathrm{T} 3$ shows that the basket cell has euchromatic nucleus $(\mathrm{N})$ with apparent nuclear pores $(\boldsymbol{\Delta})$. Its cytoplasm contains free ribosomes $(\mathrm{r})$, rough endoplasmic reticulum (Re) and numerous mitochondria (mi) with destructed cristae. (X 15000). 

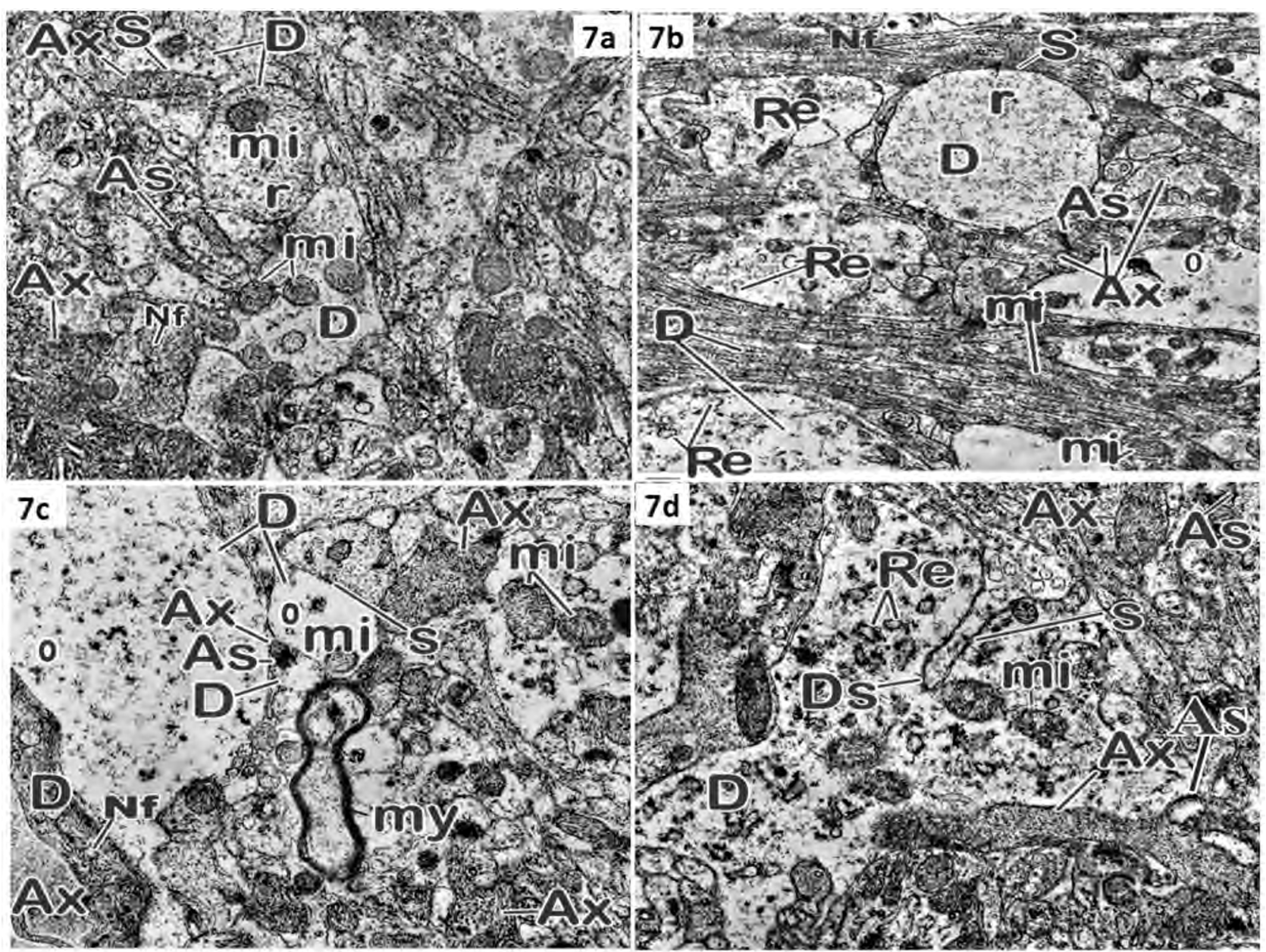

Fig. (7A): Electron micrograph of the neuropil of the molecular layer of 8 weeks control albino rat shows that the dendrites (D) contain free ribosomes ( $\mathrm{r}$ ), mitochondria (mi) and microtubules and neurofilaments (Nf). Notice that the axons (Ax) contain vesicles of varying size. Notice also the presence of synapses of symmetrical (S) and asymmetrical (As) types. (X 20000).

Fig. (7B): Electron micrograph of the neuropil of molecular layer of 8 weeks albino rat of T1 shows that some dendritic profiles (D) are swollen, have free ribosomes (r), dilated rough endoplasmic reticulum (Re), few mitochondria (mi) and areas of ill-defined structures $(0)$. However, some dendrites appear full of parallel fibers of microtubules and neurofilaments (Nf). Notice the presence of axons (Ax) and synapses of symmetrical (S) and a symmetrical (As) types. (X 20000).

Fig. (7C): Electron micrograph of the neuropil of the molecular layer of 8 weeks albino rat of T2 shows that some dendrites (D) are swollen and have few ill-defined organelles (0). Others have mitochondria (mi) and microtubules and neurofilaments (Nf). The axons (Ax) contain synaptic vesicles. Notice also the presence of myelinated nerve fibers (my) and symmetrical (S) and asymmetrical (As) synapses. (X 20000).

Fig. (7D): Electron micrograph of the neuropil of the molecular layer of the 8 weeks albino rat of T3 shows that some dendrites appear swollen (D). They contain dilated rough endoplasmic reticulum (Re) and few mitochondria (mi) with destructed cristae. The dendritic spine (Ds) can be seen. Notice the presence of axons (Ax) and symmetrical (S) and asymmetrical (As) synapses. (X 20000). 


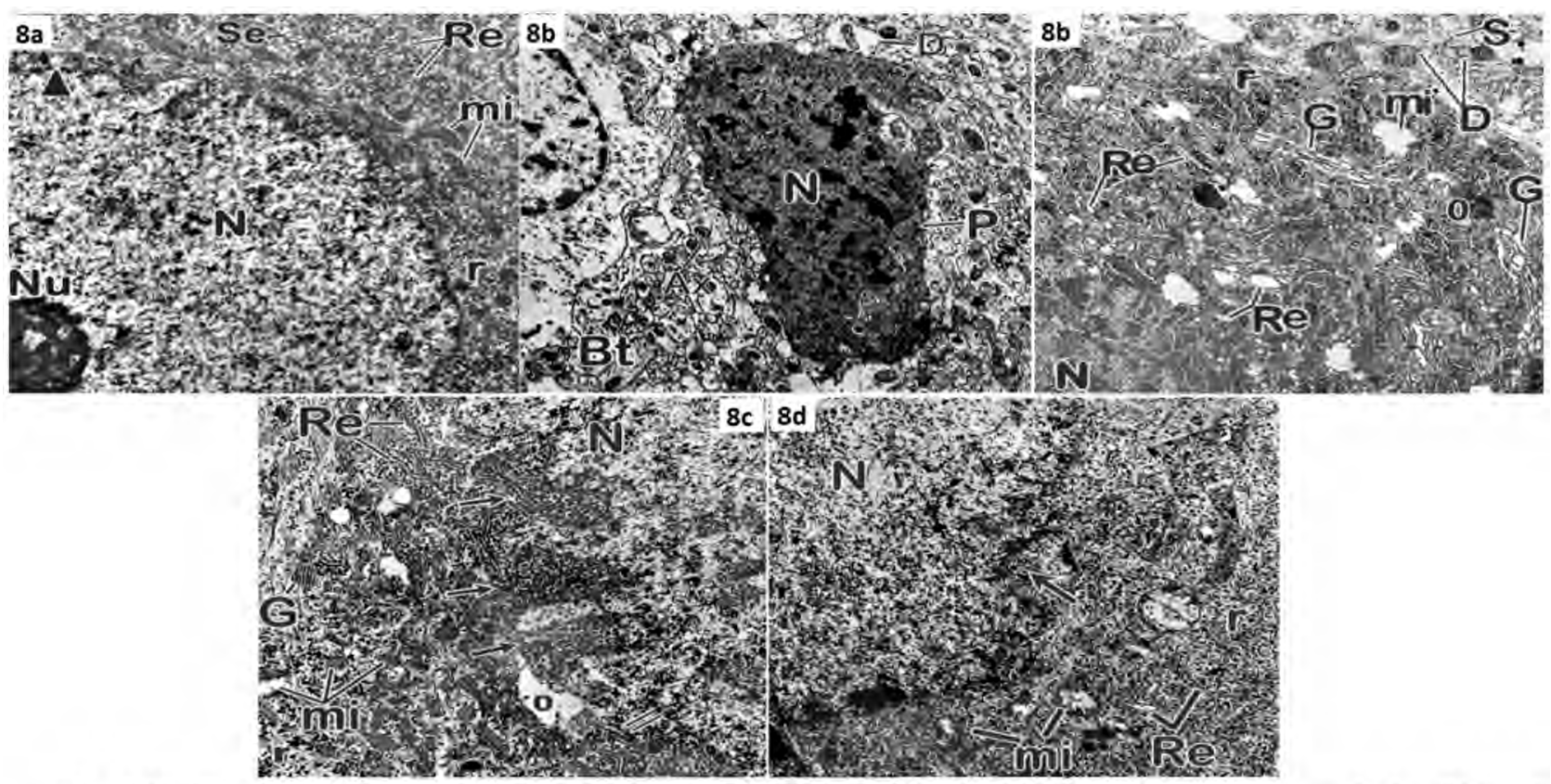

Fig. (8A): Electron micrograph of a part of Purkinje cell with euchromatic nucleus $(\mathrm{N})$ and eccentric nucleolus $(\mathrm{Nu})$ and apparent nuclear pores $(\mathbf{A})$. Its cytoplasm contains free ribosomes (r), rough endoplasmic reticulum (Re), smooth endoplasmic reticulum (Se) and mitochondria (mi). (X 15000).

Fig. (8B): Electron micrographs of the Purkinje cell layer of 8 weeks albino rat of T1 shows that one Purkinje cell (P) appears elongated and has irregular heterochromatic nucleus (N). Its cytoplasmic organelles cannot be differentiated. The other one has heterochromatic nucleus (N). Its cytoplasm contains free and clusters of ribosomes ( $\mathrm{r}$ ), dilated rough endoplasmic reticulum $(\mathrm{Re})$, some swollen mitochondria $(\mathrm{mi})$ with destructed cristae and few mitochondria with ill-defined outlines $(0)$ and swollen Golgi apparatus (G). Notice the presence of part of the basket cell (Bt). Notice also the presence of dendrites (D), axons (Ax) and symmetrical (S) synapse. (X 15000).

Fig. (8C): Electron micrograph of a part of Purkinje cell of 8 weeks albino rat of T4 shows that the Purkinje cell has euchromatic nucleus $(N)$ with shallow and deep invaginations $(\downarrow)$ with irregular and ill-defined nuclear envelope in some areas $(=)$. Its cytoplasm contains free ribosomes (r), Golgi apparatus (G), few dilated rough endoplasmic reticulum (Re), few mitochondria (mi) with destructed cristae and areas of ill-defined structures (0). (X 15000).

Fig. (8D): Electron micrograph of a part of Purkinje cell of 8 weeks offspring of T3 shows that the nucleus (N) of the Purkinje cell appears euchromatic and has many deep invaginations $(\downarrow)$. Its cytoplasm contains free ribosomes (r), few dilated rough endoplasmic reticulum ( $\mathrm{Re}$ ) and mitochondria (mi) with destructed cristae. (X 15000).

Table (1): It shows the means and standard deviations of the number of the Purkinje cells, the thickness of the molecular layer and the thickness of the internal granular layer of the cerebellar cortex of the 8 weeks old offspring. It also shows one way ANOVA statistical analysis between groups C, T1, T2 and T3. Post Hok analysis using LSD test was applied to investigate the significance between the individual groups.

\begin{tabular}{|c|c|c|c|c|c|c|c|c|c|}
\hline \multirow{2}{*}{$\begin{array}{l}\text { Groups } \\
\text { C \& T }\end{array}$} & \multirow{2}{*}{$\begin{array}{c}\text { Purkinje cell } \\
\text { Numbers } \\
\text { Mean } \pm \text { SD }\end{array}$} & \multicolumn{2}{|c|}{$\begin{array}{l}\text { One Way } \\
\text { ANOVA }\end{array}$} & \multirow{2}{*}{$\begin{array}{c}\text { Molecular } \\
\text { layer thickness } \\
\text { Mean } \pm \text { SD }\end{array}$} & \multicolumn{2}{|c|}{$\begin{array}{l}\text { One Way } \\
\text { ANOVA }\end{array}$} & \multirow{2}{*}{$\begin{array}{c}\text { Internal Granular } \\
\text { Layer Thickness } \\
\text { Mean } \pm \text { SD }\end{array}$} & \multicolumn{2}{|c|}{$\begin{array}{l}\text { One Way } \\
\text { ANOVA }\end{array}$} \\
\hline & & $\mathrm{F}$ & $p$-value & & $\mathrm{F}$ & $p$-value & & $\mathrm{F}$ & $p$-value \\
\hline Control; group C & $30 \pm 3.8$ & 27.248 & $<0.001$ & $662.1 \pm 41.2$ & 114.90 & $<0.001$ & $633.8 \pm 25.3$ & 111.44 & $<0.001$ \\
\hline $\begin{array}{l}\text { Treated; group T: } \\
\text { T1 } \\
\text { T2 } \\
\text { T3 }\end{array}$ & $\begin{array}{l}11 \pm 2.1 \\
13.4 \pm 2.1 \\
19.3 \pm 4.3\end{array}$ & & & $\begin{array}{l}228.2 \pm 20.8 \\
269.8 \pm 43.7 \\
351.9 \pm 55.9\end{array}$ & & & $\begin{array}{l}219.2 \pm 36.2 \\
300.2 \pm 41.9 \\
351.2 \pm 23.4\end{array}$ & & \\
\hline
\end{tabular}

\begin{tabular}{lccc} 
& \multicolumn{2}{c}{ Post Hoc analysis by LSD } \\
Groups C \& T & $\begin{array}{c}\text { Purkinje cell numbers } \\
p \text {-value }\end{array}$ & $\begin{array}{c}\text { Molecular layer thickness } \\
p \text {-value }\end{array}$ & $\begin{array}{c}\text { Internal Granular Layer Thickness } \\
p \text {-value }\end{array}$ \\
\hline C vs. T 1 & 0.000 & 0.000 & 0.000 \\
C vs. T2 & 0.000 & 0.000 & 0.000 \\
C vs. T3 & 0.003 & 0.000 & 0.000 \\
T1 vs. T2 & 0.001 & 0.008 & 0.011 \\
T1 vs. T3 & 0.005 & 0.005 & 0.000 \\
T2 vs. T3 & 0.023 & 0.019 & 0.048 \\
\hline
\end{tabular}

$p$-value $>0.05$ : Non significant. $\quad p$-value $<0.05$ : Significant. $\quad p$-value $<0.01$ : Highly significant.



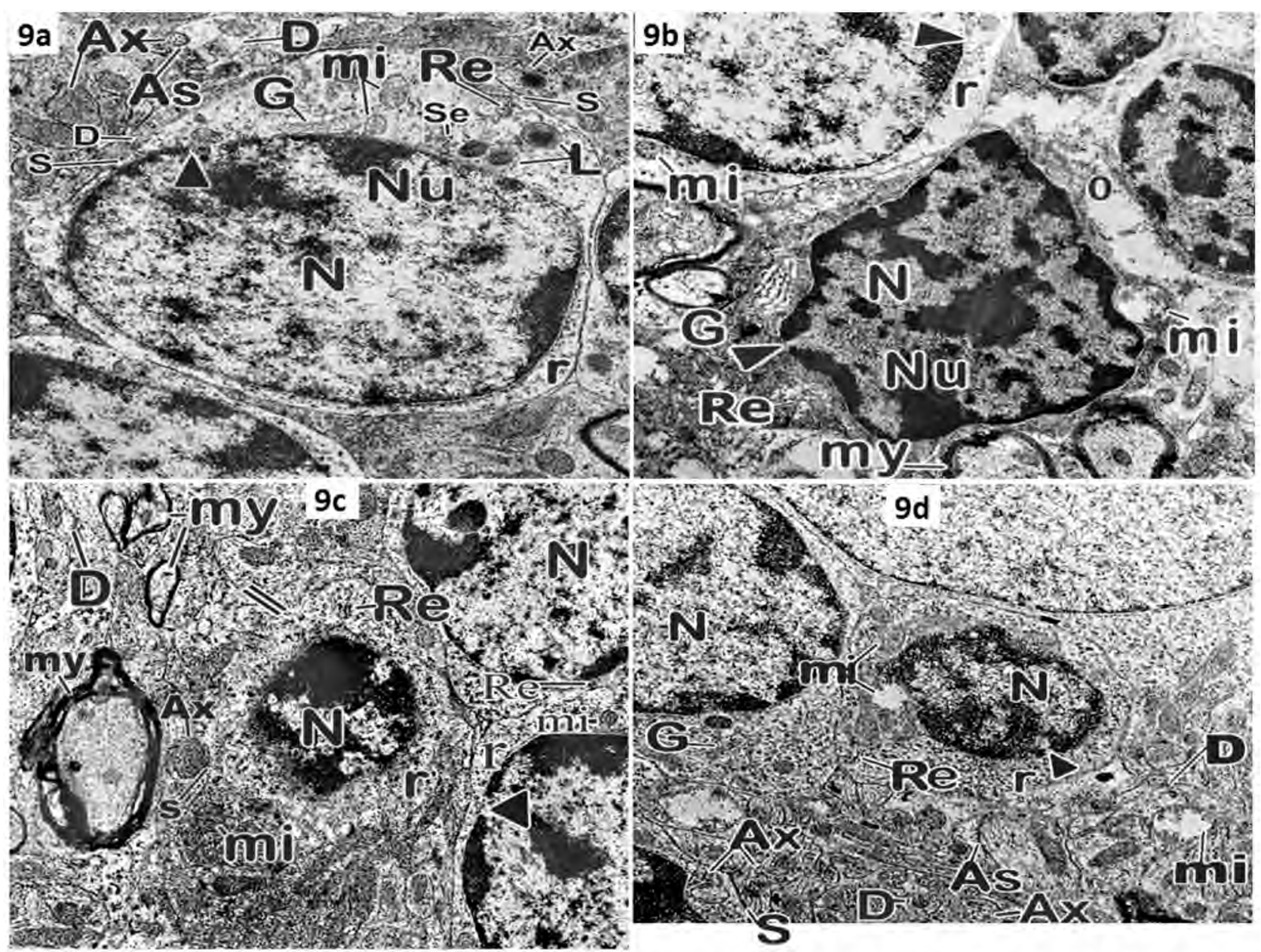

Fig. (9A): Electron micrograph of the internal granular layer of 8 weeks control albino rat shows that the granule cell has heterochromatic nucleus $(\mathrm{N})$ with eccentric nucleolus $(\mathrm{Nu})$ and apparent nuclear pores $(\boldsymbol{\Delta})$. The cytoplasm contains free ribosomes $(r)$, rough endoplasmic reticulum ( $\mathrm{Re})$, smooth endoplasmic reticulum (Se), mitochondria (mi), Golgi apparatus $(\mathrm{G})$ and lysosomes (L). Notice the presence of dendrites (D), axons (Ax) and synapses of symmetrical (S) and asymmetrical (As) types. (X 15000).

Fig. (9B): Electron micrograph of the internal granular layer of 8 weeks albino rat of T1shows that some granule cells are irregular in shape and have highly irregular condensed heterochromatic nuclei (N) with eccentric nucleoli (Nu) with apparent nuclear pores $(\mathbf{\Delta})$. Their cytoplasm contains few free ribosomes (r), elements of rough endoplasmic reticulum (Re), swollen mitochondria (mi) with destructed cristae and dilated Golgi apparatus (G). Other cells have swollen and poor cytoplasm in its organelles. Notice the presence of Myelinated nerve fibers (my) and swollen cytoplasmic processes with ill-defined organelles (0). (X 15000).

Fig. (9C): Electron micrograph of the internal granular layer of 8 weeks albino rat of T2 shows that one of the granule cells has shrunken oval nucleus $(\mathbf{N})$ with highly condensed clumps of heterchromatin and apparent nuclear pores $(\mathbf{A})$ and area of ill-defined cell membrane (=). Its cytoplasm contains few free ribosomes (r), rough endoplasmic reticulum (Re) and mitochondria (mi). Notice the presence of axons (Ax), dendrites (D), symmetrical (S) synapses and myelinated nerve fibers (my). (X 15000).

Fig, (9D): Electron micrograph of the internal granular layer of the 8 weeks albino rat of T5 shows a shrunken granule cell with irregular heterochromatic nucleus $(\mathrm{N})$ and apparent nuclear pores $(\boldsymbol{\Delta})$. Its cytoplasm contains free ribosomes $(\mathrm{r})$, Golgi apparatus (G), few small rough endoplasmic reticulum (Re) and few mitochondria with destructed cristae (mi). Notice the presence of axons (Ax), symmetrical (S) and asymmetrical (As) synapses and dendrites (D) which contain swollen mitochondria (mi) with destructed cristae. (X 15000).

\section{Discussion}

In the present work, oral administration of formaldehyde lead to delayed development of all layers of the cerebellar cortex in the form of persistence of few scattered granule cells in 4 weeks old offspring, decreased the thickness of the molecular and internal granular layers. Also the Purkinje cells were poorly developed in their shape and size, they were oval, elongated or irregular and their number decreased. The delayed development was most probably due the liability of formaldehyde 
to pass through the placental barrier and/or breast milk. Also, it could be due to direct effect of formaldehyde on the offspring where the development of the cerebellar cortex was continuous postnatally. These findings and its explanation are in agreement with [16] who reported that low birth weight and delayed development were present in the offspring of the working females exposed to formaldehyde. Also, [17] reported that formaldehyde adversely affected embryos and bone marrow cells. The embryos had cytological injury and a high rate of mortality. Whereas, the bone marrow cells had increased rates of chromosome aberrations of the peripheral lymphocytes and aneuploidy. In addition, [18] mentioned that the formaldehyde exposure during pregnancy was associated with increased risks of birth malformations. Also, [19] mentioned that oral administration of formaldehyde was associated with delayed conception and an increased risk of spontaneous abortion in the woodworker's, the laboratory personnel and the cosmetologists. The formaldehyde crossed the placenta and induced birth defects (an increase in cryptorchidism, cleft lip and palate, adhesion and reduction of cartilage of the sacrum). Moreover, [20] reported that the usual amount of formaldehyde were not high enough to enter breast milk in most workers exposed to it. But formaldehyde may enter breast milk at exposure levels that were found in some workplaces, such as anatomy and mortuary science laboratories. Also, [21,22] reported that, exposure of mice/rat to intra-peritoneal injection of formaldehyde showed reduction in the neuron counts. In addition [2], found that a remarkable decrease in both the thickness and the number of the neurons of granular layer of cerebellum was observed in the formaldehyde treated mice. The mean size and the mean number of the Purkinje cells were significantly decreased.

In the present work, the severity of delayed development of the cerebellar cortex was directly proportional with the duration and time of oral administration of the formaldehyde. Where, the thickness of the molecular and internal granular layers and the numbers of the purkinje cells of 8 weeks offspring of T1 was significantly decreased than those of T2 and T3. This finding is in agreement with $[\mathbf{2 2 , 2 3}$ who reported that the exposure to formaldehyde for long periods might lead to persistent neurotoxic effects. Histological, biochemical and pathological changes occurring due to formaldehyde exposure were morphologically variable. Such changes depend on the dose and duration of such exposure. In addition, [24] reported that the neurotoxic effects produced by the formaldehyde exposure were dependent on its concentra- tion and duration of exposure. They were more pronounced in the increased concentration and duration of the formaldehyde exposure.

In the current work, light microscopic examination of the cerebellar cortex revealed various degenerative changes in the form of pyknosis, illdefined nuclei, vacuolation in the cytoplasm and fragmented cytoplasmic processes. These degenerative changes could be due to the passage of formaldehyde through the blood-brain barrier and this most probably induced oxidative damaging effect on the brain. These findings and its explanation coincide with [23] who found that the formaldehyde was passed easily via the blood-brain barrier thus might be found in the cerebrospinal fluid. Therefore the neuroglial cells and neurons were affected. Also, [21] stated that, mice exposed to intra-peritoneal injection of formaldehyde showed dark pyknotic nuclei and degenerative damage. Also, dark neurons were observed in Wistar albino rats which exposed to formaldehyde. Also, [22,25] found histological changes in the prefrontal area of the formaldehyde-administered rats in the form of apoptotic cells with fragmented nuclei. Also, frontal cortex and hippocampus showed losing of nuclei and decreased neuronal number. Apoptotic bodies were detected in the shrunken pyknotic cells $[26,27]$. Also, reported that, in rats, the injection of formaldehyde caused severe degenerative changes, shrunken cytoplasm and extensively dark pyknotic nuclei in the neurons of the hippocampus tissues [27]. Also, mentioned that after administration of formaldehyde, it rapidly diffused to many tissues, including the brain. Therefore formaldehyde administration caused neurodegeneration and oxidative damage and increased degenerating neurons of the frontal cortex tissues. Moreover, [28] stated that intraperitoneal injection of formaldehyde induced severe neurodegenerative changes including irregular outline of the neuronal perikarya, extensively dark pyknotic nuclei. Also, focal perivascular inflammatory reaction was present in the cerebral cortex. The number of apoptotic neurons and the apoptotic cell index were increased significantly. In addition [1], found that the formaldehyde which administered orally to the rats caused mucosal ulcers, necrosis, hemorrhage and perforation in the gastrointestinal system. Subsequently, the development of metabolic acidosis, circulatory failure, hematuria, anuria and renal papillary necrosis were also present. Moreover [1], found that oral systemic application of formaldehyde impaired glomerular patterns, thickening in tubular and glomerular basal membranes, congestion of the intratubular vessels and vacuolization and dilatation in the distal tubules. Moreover, [29,30] reported 
that, the histology of the kidney, of the orally treated mice with formaldehyde, showed shrunken and degenerated tissue with ruptured and deformed glomerulus. In the liver tissue, there were severe histopathological alterations with congestion in the central vain, deleterious degenerations in the tissues, enlargement in the sinusoids, mild hemorrhages inside the tissue and reduced compactness of the cells by the formation of intercellular spaces. Inhalation of formaldehyde attributed many workers as [31] who suggested that the exposure to the formaldehyde inhalation caused severe degenerative changes in the neurons of the frontal cortex and hippocampal tissues of the rats. Furthermore, [32] found atrophy of the seminiferous tubules, decrease in the number of spermatogenic cells and disorganization of the seminiferous epithelial cells in the experimental animals which were exposed to formaldehyde by inhalation. Also disruption of the Leydig cells and spermatogenesis arrest were also observed. Also, [33,34] found apoptosis of granulosa cells and changes in the ovarian blood flow in rat ovary. Also, [35] mentioned that formaldehyde induced histopathological changes in the form of significant decrease in the number and size of the mature follicles, vascular congestion and interstitial edema. Furthermore, [36] mentioned that long-term repeated exposure to the formaldehyde inhalation in rats induced rhinitis, degeneration, necrosis, hyperplasia, and squamous metaplasia of the ciliated and non-ciliated nasal respiratory epithelium. Moreover, [37] found that inhalation of formaldehyde for three weeks in the albino rat's lungs, led to dilatation of the pulmonary blood vessels accompanied by vasculitis. This vascular reactivity characterized by presence of marked edema in the smooth muscle of the pulmonary blood vessels which infiltrated with inflammatory cell aggregations. Some specimens showed signs of epithelial dysplasia which was found in more than one layer of bronchiolar epithelium. These were characterized by appearance of multiple mitotic figures and cytoplasmic vascularity.

In the current work, electron microscopic examination of the cerebellar cortex of 8 weeks demonstrated signs of degeneration of the cytoplasmic organelles. These signs were in the form of dilated rough endoplasmic reticulum, destructed cristae of mitochondria, dilated Golgi apparatus and presence of areas of ill-defined structures. In addition, nuclear changes in the form of irregularity in the shape with presence of large condensed clumps of heterochromatin were observed. These cytoplasmic and nuclear changes were more manifested in $\mathrm{T} 1$ then $\mathrm{T} 2$ and $\mathrm{T} 3$. These results could be due to direct cytotoxic effect on neurons, effect on the function of the enzymes and/or effect on the immunity.

The cytotoxic effects of formaldehyde coincide with [38] who documented the presence of signs of degeneration after formaldehyde inhalation in adult rat. The degeneration signs were in the form of few Purkinje neurons, which exhibit strongly electron dense cytoplasm with many free ribosomes, swollen mitochondria, dilated cisterns of rough and smooth endoplasmic reticulum and hypertrophy of Golgi complexes [39,40]. Also, reported that, formaldehyde developed cytotoxic effect by forming a cross-bond between protein and DNA, resulting in a damage that led to cancer and destruction of the cell [37]. Also, examined the lungs of three weeks rats after formaldehyde inhalation. The examination showed that the lung cells had irregular hyperchromatic nuclei with indented nuclear envelope and presence of chromatin clumps adjacent to the nuclear membrane (peripheral heterochromatin). Dilatation and vesiculation of the rough endoplasmic reticulum of the epithelial cells were present. The reticulum appeared as numerous rounded vesicles of variable size that contained light electron dense granular matrix. Moreover, [41] observed that, after intraperitoneal injection of formaldehyde in rat testes, the cell sequences in the germ cells were impaired. The structures of mitochondrial cristae in cells were disrupted, the rough endoplasmic reticulum sacs were extended, and there was intracellular vacuolization. Mitochondrial cristae degeneration was observed.

The enzymatic effects of formaldehyde can be explained by $[25,42]$ who stated that formaldehyde had a strong tendency to combine with the proteins, nucleic acids (DNA, RNA), and unsaturated fatty acids through non enzymatic means, which led to allergic reactions, cytotoxicity, genotoxicity, mutagenic, and slight carcinogenic actions. In addition, [21] reported that the brain and the nervous system might be prone to radical damage of formaldehyde, as the brain had a high content of easily preoxidizable unsaturated fatty acids and the brain requires very high amounts of oxygen per unit weight [21, 43-45]. Also, mentioned that the formaldehyde affected cerebellar oxidant/antioxidant systems and caused oxidative damage. The cerebellar catalase and superoxide dismutase enzymatic activities of the rats exposed to formaldehyde were significantly lower than those of the rats in the control group, which indicated that formaldehyde disrupted the antioxidant defense mechanism of the cerebellar cortex, leading to oxidative stress formation. Xanthine oxidase was an enzyme that functioned both in purine and free radical metabolism. The increased 
xanthine oxidase activity might cause further tissue damage because of its reactive oxygen species generating effect. Although reactive oxygen species were essential for many normal biological processes and were produced physiologically. The excessive production and accumulation of the reactive oxygen species could become hazardous to the cells and tissues. In addition, [19] found that oral administration of formaldehyde affected the enzyme function in the mitochondria, lysosomes and rough endoplasmic reticulum. Moreover, [23] observed that the exposure to formaldehyde during the early postnatal period caused an increase in the activity of glutathione peroxidase and levels of malondialdehyde and nitric oxide, and a decrease in superoxide dismutase activity at postnatal day 30 in the rat cerebellum.

The immunological effect of formaldehyde was reported by [46] who found that long-term exposure to formaldehyde was associated with auto antibodies, immune activation, and formaldehyde-albumin adducts in patients occupationally exposed to formaldehyde. Moreover, [21,22,25] revealed that the exposure to the formaldehyde under similar conditions increased apoptosis in the rat prefrontal cortex and caused an increase in the immune reactivity of Bax, which was a pro-apoptotic protein. Also, [24] stated that chronic exposure to formaldehyde had been associated with immunological hypersensitivity as measured by elevated circulating IgG and $\operatorname{IgE}$ auto antibodies to human serum albumin. In addition, a decrease in the proportion of T-cells was observed, indicating altered immunity.

\section{Conclusion:}

It could be concluded that the oral administration of formaldehyde caused delayed development and induced different histological changes in the cerebellar cortex of the offspring's albino rats. These effects were directly proportional with the duration and time of its administration. The exposure to formaldehyde must be avoided as much as possible especially during pregnancy, lactation and early life.

\section{Recommendations:}

The current work suggested that the use of formaldehyde causes serious effects on cerebellar cortex of albino rats, especially if consumed regularly. Therefore, strict law needs to be formulated to prevent adding formaldehyde to the food staff. This should also be reflected in our national health policy. Everybody should wash vegetables and fruits properly before consuming to prevent harmful effect of formaldehyde and searching out safe food preservative.

\section{References}

1- INCI M., ZARARSIZ I., DAVARCI M. and Gorur S.: Toxic effects of formaldehyde on the urinary system. Turkish Journal of Urology, 39 (1): 48-52, 2013.

2- MOHAMMADI S.: Protective effect of N-acetyl cysteine against formaldehyde-induced neuronal damage in cerebellum of mice. Pharmaceutical Sciences, 20: 61-5, 2014.

3- SUN X., LIN J., GUAN H., LI L., SUN L., WANG Y. and WANG X.: Complete oxidation of formaldehyde over TiO 2 supported subnanometer Rh catalyst at ambient temperature. Applied Catalysis B Environmental, 226: 575-84, 2018.

4- PANDEY C.K., AGARWAL A., BARONIA A. and SINGH N.: Toxicity of ingested formalin and its management. Hum. Exp.Toxicol., 19: 360-6, 2000.

5- BARCELLONA P.S., FANELLI O. and CAMPANA A.: Teratological study of etoperiodine in the rat and rabbit. Toxicology, 8 (1): 87-94, 1977.

6- EFSA (European Food Safety Authority): Endogenous formaldehyde turns over in humans compared with exogenous contribution from food sources. EFSA, Journal, 12 (2): 35-50, 2014.

7- CLARK G.: "Staining procedures". 4 th ed. Williams and Wilkins, pp. 13-4, 1981.

8- DAWSON R.M.C., ELLIOTT D.C., ELLIOTT W.H. and JONES K.M.: "Data for biochemical research". 3 rd ed. Oxford University Press, New York, pp. 39-40, 1986.

9- BLOCK S.S.: "Disinfection, sterilization and preservation". 4th ed. Lea and Febiger, Philadelphia, pp. 582-3, 1991.

10- CHEUNG A.F.P. and LAM D.S.C.: Formalin: A formaldehyde analogue. Can. J. Ophthalmology, 229: 252-3, 2017.

11-PAGET G.C. and BARNES J.M.: "Toxicity in evaluation of the drug activities pharmaceutics". 1 sted. Lournace and Bacharachia, Academic Press, London and New York, pp. 1-13, 1964.

12- SUVARNA S.K., LAYTON C. and BANCROFT J.D.: "Theory and practice of histological techniques". 7 th ed. London, Churchill Livingstone, Elsiver, pp. 173-87, 2013.

13-BANCROFT J.D. and GAMBLE M.: "Theory and practice of histological techniques". 6 th ed. Churchill Livingston, Edinburg, pp. 340-8, 2008.

14- DRURY R.A.B. and WALLINGTON E.A.: "Carleton's histological technique". 5 th ed. Published by Oxford University Press, London, New York, Toronto, pp. 35590, 1980.

15- MOULD R.F.: "Introductory medical statistics". 2 nd ed. Adam Hilger, Bristol and Philadelphia, pp. 17-26, 1989.

16- IPCS (International Program on Chemical Safety): Formaldehyde, World Health Organization, (Environmental Health Criteria 89), Geneva, 115-30, 1989.

17- SURUDA A., SCHULTE P. and BOENIGER M.: Cytogenetic effects of formaldehyde exposure in students of 
mortuary science. Cancer Epidemiol. Biomarkers Prev., 2: 453-560, 1993.

18- DUONG A., STEINMAUS C., McHale C.M., VAUGHN C.P. and ZHANG L.: Reproductive and developmental toxicity of formaldehyde. A systematic review. Mutat. Res., 728: 118-38, 2011.

19- JACK D., THRASHER E. and KILBURN K.H.: Embryo toxicity and teratogenicity of formaldehyde. Archives of Environmental Health. An International Journal, 56 (4): 300-11, 2010.

20- NIOSH (National Institute for Occupational Safety and Health): Reproductive health and the workplace, formaldehyde. Workplace Safety and Health Topics, 2017.

21- GUREL A., COSKUN O., ARMUTCU F., KANTER M. and OZEN O.A.: Vitamin E against oxidative damage caused by formaldehyde in frontal cortex and hippocampus: Biochemical and histological studies. J. Chem. Neuroanat., 29: 173-8, 2005.

22- ZARARSIZ I., SARSILMAZ M., TAS U., KUS I., MEYDAN S. and OZAN E.: Protective effect of melatonin against formaldehyde-induced kidney damage in rats. Topical Ind. Health, 23 (10): 573-9, 2007.

23- SONGUR A., OZEN O.A. and SARSILMAZ M.: The toxic effects of formaldehyde on the nervous system. Reviews of Environmental Contamination and Toxicology, 203: 105-18, 2010

24- ABDU H., KINFU Y. and AGALU A.: Toxic effects of formaldehyde on the nervous system. International Journal of Anatomy and Physiology, 3 (3): 50-9, 2014.

25- ZARARSIZ I., SONMEZ M.F., YILMAZ H.R., TAS U., KUS I., KAVAKLI A. and SARSILMAZ M.: Effects of omega-3 essential fatty acids against formaldehyde induced nephropathy in rats. Toxicology and Industrial Health, 25: 223-9, 2006.

26- OZDEM T.A., SARSILMAZ M., KUS I., SONGUR A., OZYURT H., AKPOLAT N. and OGETURK M.: Caffeic acid phenethyl ester (CAPE) prevents formaldehydeinduced neuronal damage in hippocampus of rats. Neuroanat, 6: 66-71, 2007.

27- KANTER M.: Protective effects of Nigella sativa on formaldehyde induced neuronal injury in frontal cortex. Mol. Hist. J., 8 (1): 1-8, 2010.

28- MOHAMAD A.E., ESSA T.M. and ATA H.S.: Nigella sativa protects against formaldehyde induced neurotoxicity in the rat frontal cortex. Turkish Society of Anatomy and Clinical Anatomy, 9 (3): 117-27, 2015.

29- ABDULQADER S.Z. and MUSTAFA I.A.: The protective role of vitamin $\mathrm{C}$ against formaldehyde induced hepatotoxicity and nephrotoxicity in male rats. IOSR Journal of Pharmacy and Biological Sciences, 9 (3): 21-6, 2014.

30- MAMUN M.A., RAHMAN M.A., ZAMAN M.K., FERDOUSI1 Z. and ABU REZA M.: Toxicological effect of formalin as food preservative on kidney and liver tissues in mice model. IOSR Journal of Environmental Science, Toxicology and Food Technology, 9 (8): 47-51, 2014.
31- SONGUR A., AKPOLAT N., KUS I., OZEN O.A., ZARARSIZ I. and SARSILMAZ M.: The effects of the inhaled formaldehyde during the early postnatal period in the hippocampus of rats: A morphological and immunehistochemical study. Neurosci. Res. Commun., 33: 16878, 2003.

32- ZHOU D.X., QIU S.D., WANG Z.Y. and ZHANG J.: Effect of tail-suspension on the reproduction of adult male rats. Zhonghua Nan Ke Xue Za Zhi, 12: 326-9, 2006.

33- GUVEN S., MUCI E., UNSAL M.A., YULUG E., ALVER A. and DUMAN M.K.: The effects of carbon dioxide pneumoperitoneum on ovarian blood flow, oxidative stress marker and morphology during laparoscopy: A rabbit model. Fertility and Sterility, 93 (4): 1327-32, 2010.

34- MIYAMOTO K., SATO E.F., KASAHARA E., JIKUMARU M., HIRAMOTO K. and TABATA H.: Effect of oxidative stress during repeated ovulation on the structure and functions of the ovary, oocytes and their mitochondria. Free Radical Biology and Medicine, 49 (4): 674-81, 2010.

35- WANG H., WANG X., ZHOU D., ZHENG L., ZHANG J., HUO Y. and TIAN H.: Effects of low-dose, long-term formaldehyde exposure on the structure and functions of the ovary in rats. Toxicology and Industrial Health, 29 (7): 609-15, 2012.

36- YORGANCILAR E., DEVECI E. and DEVECI S.: Effects of formaldehyde on respiratory mucosa in rats. Int. J. Morphol., 30 (2): 521-3, 2012.

37- MOHAMED A.M., EL-ASHTOKHY M., AHMED H.M. and IBRAHIM O.Y.: Anatomical and histological effects of formaldehyde inhalation on the lung of albino rat. Journal of American Science, 8 (9): 395-404, 2012.

38- SCHERINI F., BOLCHI F., BIGGIOGERA M. and BERHOICHI G.: Further evidence of different morphofunctional aspects in the Purkinje cell population of adult rat cerebellum. Journal of Submicroscopic Cytology, 13: 17-29, 1981.

39- KILBURN K.H., WARSHAW R. and THORNTON J.C.: Formaldehyde impairs memory, equilibrium, and dexterity in histology technicians: Effects which persist for days after exposure. Arch. Environ. Health, 42: 117-20, 1987.

40- SAITO Y., NISHIO K., YOSHIDA Y. and NIKI E.: Cytotoxic effect of formaldehyde with free radicals viaincrement of cellular reactive oxygen species. Toxicology, 210: 235-45, 2005.

41- ULUCAM E. and BAKAR E.: The effect of proanthocyanidin on formaldehyde-induced toxicity in rat testes. Turkish Journal of Medical Sciences, 46: 185-93, 2016.

42- USANMAZ S.E., AKARSU E.S. and VURAL N.: Neurotoxic effects of acute and subacute formaldehyde exposures in mice. Environmental Toxicology and Pharmacology, 11 (2): 93-100, 2002.

43- OZYURT B., IRAZ M., KOCA K., OZYURT H. and SAHIN S.: Protective effects of caffeic acid phenethylester on skeletal muscle ischemia-reperfusion injury in rats. Molecular Cellular Biochemistry, 292: 197-203, 2006.

44- BAS O., SONGUR A., SAHIN O., MOLLAOGLU H., OZEN O.A., YAMAN M., ESER O., FIDAN H. and 
YAGMURCA M.: The protective effect of fish n-3 fatty acids on cerebral ischemia in rat hippocampus. Neurochem. Int., 50: 548-54, 2007.

45- ZARARSIZ I., MEYDAN S., SARSILMAZ M., SONGUR A., OZEN O.A. and SOGUT S.: Protective effects of omega-3essential fatty acids against formaldehyde-induced cerebellar damage in rats. Toxicol. Ind. Health, 27 (6): 489-95, 2011.

46- THRASHER J.D., BROUGHTON A. and MADISON R.: Immune activation and auto antibodies in humans with long term inhalation exposure to formaldehyde, Archive Environ. Health, 45 (4): 217-23, 1990.

\section{التآثير الخلوى للفورمالدهيد كحافظ للطعام على قشرة مخيخ الجرئرذ الآبيض}

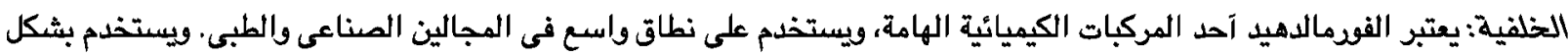
غير قانونى وبكميات كبيرة للحفاظ على آنواع مختلة من المواد الغذائية. وقد آثر ذلك على الجهاز العصبى المركزيى وخاصة الثئ قشرة المخيخ. الهدف من هذا العمل: يهدف هذا العمل إلى تقييم مدى التغيرات النسيجية فى قشرة المخيخ لنسل الجرذان البيضاء التى قد تكون مستحثة

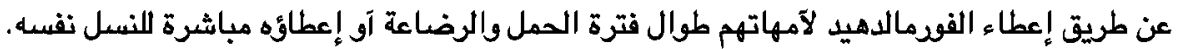

المواد والطرق: إستخدم فى هذا العمل الفورمالدهيد (9.1عمجم/شخص/اليوم) وتعتبر هذه الجرعة الحد الآقصى اللتعرض الغذائي. وكانت

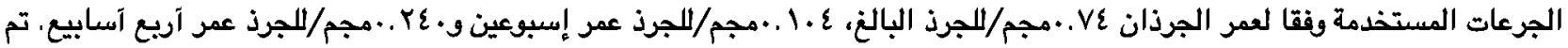

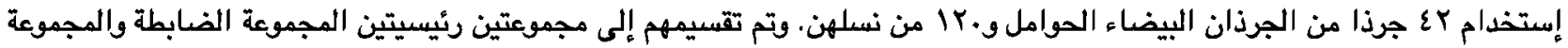

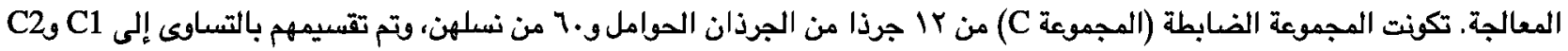

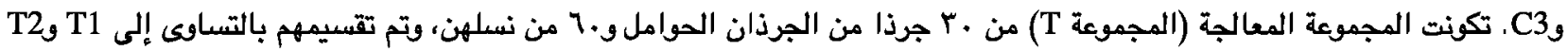

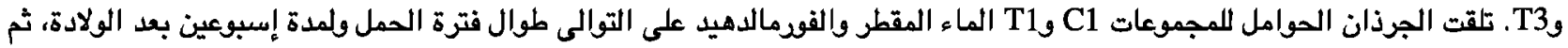

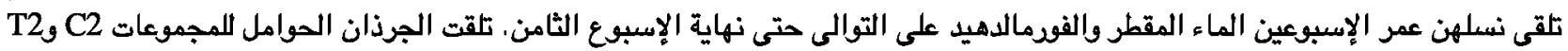

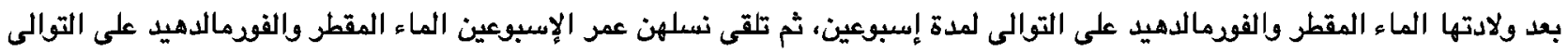

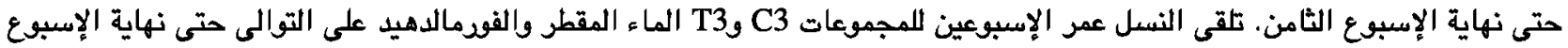

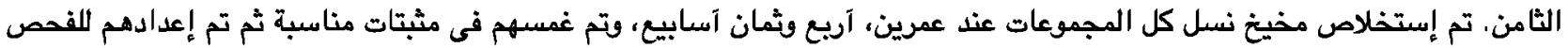

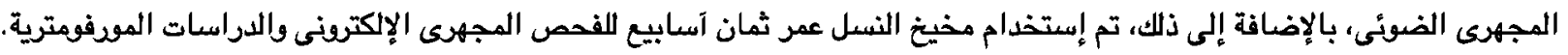

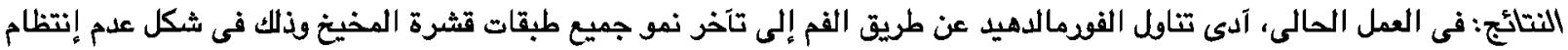

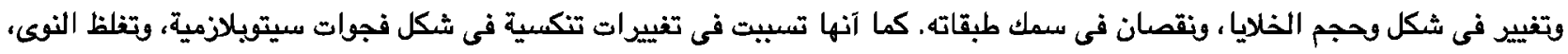

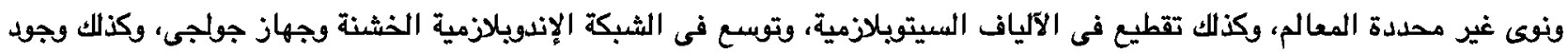
ميتوكوندريا ذات كريستيا مدمرة، ووجود مناطق ذات فئ فعالم غير واضحة.

الإستتاج: يمكن الإستتاج آن تناول الفورمالدهيد عن طريق الفم تسبب فى تآخر نمو قشرة المخيخ وتسبب كذالك فى تغييرات نسيجية

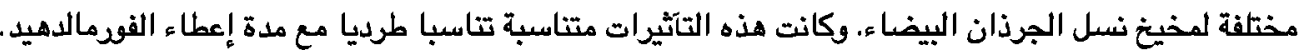

